\title{
Okul Yöneticilerinin Otantik Liderlikleri ile Öğretmenlerin Motivasyon ve İş Doyumu Arasındaki İlişkinin İncelenmesi*
}

\author{
Durdağ 1 AKAN*** Muhammet Emre KILIÇ***
}

- Geliş Tarihi: 17.12.2020 • Kabul Tarihi: 29.04.2021 • Çevrimiçi Yayın Tarihi: 29.04.2021

\section{$\ddot{O} z$}

$\mathrm{Bu}$ çalışmanın amac1, otantik liderliğin okullarda öğretmenlerin motivasyonu ve iş doyumu üzerindeki etkisini belirlemektir. Bu araştırmada açımlayıcı sıralı karma yöntemi ile yürütülmüştür. Araştırmanın nicel kısmında ilişkisel tarama modeli ve nitel kısmında durum çalışması kullanılmıştır. Araştırmanın nicel kısmı 649 ve nitel kısmı ise 11 öğretmeni ile yürütülmüştür. Araştırmanın bulgularına göre otantik liderlik, motivasyon ve iş doyumu arasında orta düzeyde, pozitif ve anlamlı bir ilişki bulunmuştur. Otantik liderlik motivasyonla birlikte iş doyumunu açıkladığı gözlemlenmiştir. Araştırmaya göre iletişim, adalet, şeffaflık, problem çözme, cesaretlendirme ve güven öğretmen motivasyonunu sağlayan özgün liderlik davranışlarıdır. Ayrıca, performans, başarı, mutluluk ve kendini geliştirme iş doyumunu sağlayan motivasyonel davranışlardır. Araştırmaya göre geri bildirim, takdir, destek, adalet, problem çözme ve olumlu okul iklimi iş doyumunu sağlayan otantik liderlik davranışlarıdır.

Anahtar Kelimeler: Okullar, yönetim, örgütsel davranış

Atıf:

Akan, D. ve Kılıç, M.E. (2021). Okul yöneticilerinin otantik liderlikleri ile öğretmenlerin motivasyon ve iş doyumu arasındaki ilişkinin incelenmesi. Pamukkale Üniversitesi Eğitim Fakültesi Dergisi, 53, 429-456.doi:10.9779.pauefd.842331

\footnotetext{
* $\mathrm{Bu}$ araştırma 2. Yazarın doktora tezinden üretilmiştir.

** Doç. Dr.,Atatürk Üniversitesi Eğitim Yönetimi Bölümü, ORCID ID: 0000-0002-5397-8470, durdagiakan @ atauni.edu.tr ***Öğretmen, Özel Aydın Doğan İlköğretim Okulu, ORCID ID:0000-0001-5511-8573, muhammetemrekilic25@gmail.com
} 


\section{Giriș}

Okul, toplumun ve bireyin olumlu ve olumsuz deneyimlerinden açık yapısı sebebiyle doğrudan veya dolaylı etkilenmektedir. $\mathrm{Bu}$ sebeple okullar, sürekli olarak farklılaşan ve devam eden sorunların çözümü ve yenileşme ihtiyacını yönetmek için olumlu yönetici davranışlarına ihtiyaç duymaktadır. Öğretmenlerin iş doyumu ve motivasyonları bu anlamda yönetici etkililiği hakkında önemli oranda ipucu verebilmektedir. Yöneticilerin ortaya koyacağı adaletli, tarafsız, şeffaf ve kendini bilen davranışları eğitim kurumlarının süregelen ve güncel sorunları için önemli bir çözüm kaynağı olabileceği düşünülmektedir.

Liderlik örgütün amaçlarını gerçekleştirmek için bir küme ya da grubu etkileme davranışı olarak adlandırılabilir. Özellikle okul yöneticileri okulun amaçları ile çalışanların gereksinimleri arasında bir denge kurmaları örgütsel bir gereklilik olarak düşünülmelidir (Bursalığlu, 1994; Conlow, 1999; Glynn \& Dejordy, 2010; Robbins, 1998; Zel, 2011). Liderliği oluşturan yapı taşlarından bazılarının dürüstlük, karakter, güvenilirlik ve saygınlık gibi özellikler olduğu söylenebilir (Barutçugil, 2014). Takipçilerin davranışlarını etkilemede gözlenen davranışlarından birisi değer temelli liderlik teorileridir. Dinh vd., (2014) değer temelli liderlik teorilerini otantik liderlik, etik liderlik, hizmetkar ve ruhani liderlik davranışlarını bünyesinde barındıran bir kavram olarak tanımlamıştır. Otantik liderlik davranışlarının öğretmenleri birçok yönden olumlu etkileyeceği düşünülmektedir.

Otantik liderler, kendilerini tanıyan kişilerdir (Ilies, Nahrgang ve Morgeson, 2005). İçselleştirilmiş bir ahlaki anlayışa ve değerler dizisine sahiptirler (George ve Sims, 2010; Walumbwa, Avolio, Gardner, Wernsing ve Peterson, 2008). İlişkilerinde şeffaf olma, güvenilir bir kişiliğe sahip olma, disiplinli olma, özgün davranışlara sahip olma, duyarlılık, çalışanlara model olma ve işlerini destekleme gibi niteliklere sahiptirler (Begley, 2004; Gardner, Avolio, Luthans, May ve Walumbwa, 2005; Shamir ve Eilam, 2005).

Otantik liderliğin boyutlarını ele alan çalışmalar tarihsel bir düzlem içinde incelendiğinde ise ilk olarak Kernis (2003) otantik liderliğin boyutlarını farkındalık, tarafsız değerlendirme, davranış ve ilişkisel otantiklik olarak ele aldığı görülmektedir. Kernis (2003) yaptığı modeli temel alarak oluşturulan bir diğer kavramsal çerçeve ise Ilies, Morgeson \& Nahrgang (2005) tarafından yapılmıştır. Bu sınıflandırmada ise Ilies vd. (2005) otantik liderliğin boyutlarını öz-farkındalık, dengeli değerlendirme, otantik davranma ve otantik ilişkisel yönelim olarak sınıflandırmışlardır. Literatür incelendiğinde otantik liderlikle ilgili yapılan çalışmalarda genellikle Walumbwa vd., (2008) tarafindan ortaya konulan teorik alt 
yapının kullanıldığı görülmektedir. Walumbwa vd. (2008) otantik liderliğin boyutlarını ilişkilerde şeffaflık, içselleştirilmiş ahlak anlayışı, öz farkındalık ve dengeli değerlendirme olarak ortaya koymuştur.

Avolio \& Gardner (2005) yaptıkları araştırmada otantik liderliğin unsurlarını ortaya koymuşlardır. Bu unsurlar sırasıyla; pozitif psikolojik sermaye, ahlaki perspektif, liderin benlik bilinci, öz-düzenlemesi, takipçinin benlik bilinci, performansı ve gelişimidir. Bununla bağlantılı olarak, Luthans, Norman, \& Hughes (2006) otantik liderliğin boyutlarını özfarkındalık, öz-denetim, dengeli değerlendirme, rasyonel şeffaflık ve otantik davranma olarak sinıflandırmaktadır.

Araştırmalar, otantik liderliğin iş performansı, örgütsel bağlılık ve iş doyumu dahil olmak üzere birçok örgütsel sonuçla ilişkili olduğunu göstermektedir (Clapp, Vogelgesang ve Avey, 2009; Giallonardo, Wong ve Iwasiw, 2010; Walumbwa ve diğerleri, 2008; Walumbwa, Wang, Wang, Schaubroeck ve Avolio, 2010; Walumbwa vd., 2011; Wong, Laschınger ve Cummings, 2010; Zamahani, Ghorbani ve Rezaei, 2011). Otantik liderliğin öğretmenlerin motivasyonu ve iş doyumu gibi birçok değişkeni olumlu etkilediği düşünülmektedir. Başka bir deyişle, otantik liderliğin motivasyonu etkilediği düşünülmektedir.

Motivasyon, temel olarak daranışların neden ortaya çıktığını ve insanların ihtiyaçlarını tanımlar. Yani motivasyonun kişinin bir davranışa karşı tutumu olduğu veya bu davranışı neden tekrarladığının açıklaması olduğu söylenebilir (Elliot ve Covington, 2001). Motivasyon, temel olarak davranışı uyaran durum olarak adlandırılır. Motivasyon genellikle bireyi harekete geçiren ve yönlendiren içsel bir süreç olarak tanımlanır (George, Jones ve Sharbrough, 1996; Hoy ve Miskel, 2010). Motivasyon kavramı incelendiğinde öncelikle kişilik, organizasyon, öğrenme ve performans gibi birçok konuyla ilgili olduğu görülmektedir (Black ve Deci, 2000; Dweck ve Leggett, 1988; Lawler, 1973; Maslow, Frager ve Cox, 1970). Literatür incelendiğinde otantik liderliğin motivasyonu olumlu yönde etkilediği gözlemlenmiştir. Bunun yanında otantik liderliğin iş doyumunu etkilediği düşünülmektedir.

İş doyumu, bir kişinin işini, iş deneyimini (Locke, 1976) veya işiyle ilgili memnuniyetini ve düşüncelerini belirtir (Colquitt, Lepine ve Wesson, 2009; Hellriegel, 2001; Robbins \& Judge, 2015). Yapılan araştırmalar incelendiğinde iş doyumunun yaş, eğitim, sosyo-ekonomik durum ve mesleki doyumla ilişkili olduğu ortaya çıkmıştır (Can ve 
Soyer, 2008; Toker, 2007). Özetle, iş doyumu bir bireyin işine karşı genel tutumudur (Robbins, DeCenzo ve Coulter, 2008).

Öğretmenlerin yüksek düzeyde sahip oldukları iş doyumlarının performanslarında doğrudan ve dolaylı olarak etili olması, iş doyumunun öğretmenler açısından önemini ortaya koymaktadır (Yazıcıoğlu, 2010; Yıldırım, Akan, \& Yalçın, 2017). Öncelikle öğretmenlerin iş doyumunu etkileyen faktörlerin gelecek kaygısı, başarı ve başkalarına yararlı olma faktörleri olduğu bilinmektedir (Karataş \&Güleş, 2010). Özellikle etik liderlik gibi değer temelli yönetici davranışlarının öğretmenlerin iş doyumlarını olumlu yönde etkilediği bilinmektedir ( Madenoğlu, Uysal, Sarıer, \& Banoğlu, 2014;Yılmaz, \& Ceylan, 2011). Buna bağlı olarak özel eğitim kurumlarında çalışan öğretmenlerin iş doyumlarının yöneticilerinin davranışlarından devlet okullarında çalışan öğretmenlerden daha fazla olumlu yönde etkilendiği de bilinmektedir (Karaköse \& Kocabaş, 2006).

Birçok çalışma liderlik ve motivasyonun birçok yönden ilişkili olduğunu ortaya çıkarmıştır (Benson, 2008; Isaac, Zerbe ve Pitt, 2001). Motivasyon ve liderlik arasında güçlü bir ilişkiye sahip olmanın yanı sıra organizasyonlarda verimliliği artırmak için motivasyonun çok önemli olduğu söylenebilir (Serinkan, 2008; Y1lmazer, 2013). Yapılan çalışmalarda otantik liderliğin çalışanların güçlendirilmesi, işbirliği duygusu ve tükenmişlik gibi motivasyonu etkileyen konularla ilişkili olduğu gösterilmiştir (Henderson ve Hoy, 1982; Walumba vd., 2008; Wong ve Cummings, 2009). İşyerinde çalışan motivasyonunu artırmak isteyen kuruluşlar, çalışanlarında otantik liderliği ve personel gelişimini teşvik etmek isteyebilirler. İşyerinde çalışan motivasyonunu artırmanın birçok yolu olmasına rağmen, liderlik gelişimi kuruluşlar için güçlü bir araçtır. Otantik liderlik uygulamaları, organizasyonlarda çalışanları güçlendirmenin bir yolu olduğu söylenebilir (Wernsing, 2018).

Otantik liderliğin iş çıktıları ve performansa etki ettiğini vurgulanmaktadır. Yani liderlik davranışının çalışanların iş doyumu gibi birçok davranışına olumlu yönde etki ettiği gözlenmektedir. Wong \& Cummings (2009). Otantik liderlik, yeni becerilerin keşfedilmesini sağlayarak özerkliği, yetkinliği ve iş doyumunu mümkün kılarak otantik liderlerin takipçinin gelişimini sağlamadaki kilit rolünü vurgulanmaktadır (Wong \& Laschinger, 2013). İş doyumunun otantik liderlik davranışından olumlu etkilendiğini gösteren pek çok çalışma bulunmaktadır (Darvish ve Rezaei, 2011; Datta, 2015; Wong ve Laschinger, 2013). Ayrıca otantik liderliğin performans ve iş doyumu ile pozitif bir ilişkisi olduğu gözlemlenmiştir (Giallonardo, Wong ve Iwasiw, 2010; Wong ve Laschinger, 2013). McNeese-Smith (1997), yöneticilerin davranışlarının çalışanların iş doyumu, üretkenliği ve 
bağlılığını etkilediğini bulmuştur. Araştırmalar, otantik liderliğin çalışanların iş doyumunu doğrudan ve dolaylı olarak etkilediğini ve aralarında bir ilişki olduğunu ortaya çıkarmıştır (Giallonardo, Wong ve Iwasiw, 2010; Azanza, Moriano ve Molero, 2013; Wong ve Laschinger, 2013). Özetle, otantik liderlik davranışının okullarda iş doyumunu olumlu etkilediği düşünülmektedir.

Kuruluşun üyelerini neyin motive ettiğini anlamak önemlidir. $\mathrm{Bu}$ sayede motive olmaları daha kolay olacaktır. Hem motivasyonu hem de iş doyumunu etkileyen faktörler oldukça yüksektir. Bu bağlamda bakıldığında iş doyumu sağlamanın anahtarlarından birinin motivasyon olduğu söylenebilir. Motivasyon ile iş doyumu arasında karşılıklı bir ilişki vardır. İş doyumu olan bir birey motive edilebilir. Aynı şekilde motive olmuş bireyler de işlerinden mutlu olacaktır. Sonuç olarak, motivasyon iş doyumu oluşturabilir. Kişi işinden almak istediğini başarırsa iş doyumuna sahip olacaktır. (Alsat, 2016; Kundak, Üzel, Keleş ve Eğicioğlu, 2015; Şimşek, Çelik ve Akgemci, 2008). Yapılan literatür taramasının sonucunda, yöneticilerinin otantik liderlik davranışlarının öğretmenlerin motivasyonu ve iş doyumlarını olumlu yönde etkilediği söylenebilir.

\section{Araştırmanın Amacı}

$\mathrm{Bu}$ çalışmanın amacı, otantik liderliğin öğretmenlerin motivasyonu ve iş doyumu üzerindeki etkisini belirlemektir. Eğitim yöneticilerinin otantik liderlik davranışlarının öğretmenlerin motivasyonu ve iş doyumu üzerindeki etkisini belirlemek için bu model nitel araştırmalarla desteklendi. Araştırmanın bu genel amacına ulaşmak için geliştirilen nicel ve nitel araştırma soruları aşağıda sunulmuştur.

\section{Nicel araştırma sorulart}

S1. Otantik liderlik ile öğretmenlerin motivasyonu ve iş doyumu arasında bir ilişki var mı?

S2. Otantik liderlik öğretmenlerin motivasyonunu hangi yön ve düzeyde etkiler?

S3. Öğretmenlerin motivasyonu iş doyumlarını hangi yön ve düzeyde etkiliyor?

S4 Otantik liderlik, öğretmenlerin iş doyumlarını hangi yön ve düzeyde etkiler?

S5. Öğretmenlerin motivasyonu otantik liderlikle birlikte iş doyumu değişimini anlamlı bir şekilde açıklıyor mu? 


\section{Nitel araştırma soruları}

S6. Öğretmenler motivasyonlarını etkileyen otantik liderlik davranışları hakkında ne düşünüyor?

S7. Öğretmenler iş doyumlarını etkileme motivasyonları hakkında ne düşünüyor?

S8. Öğretmenler iş doyumlarını etkileyen otantik liderlik davranışları hakkında ne düşünüyor?

\section{Yöntem}

Bu çalışmada, karma yöntemle açıklayıcı sıralı tasarım kullanılmıştır. Nicel aşamayı nitel bir aşama izlediği için bu yönteme sıralı denir (Creswell, 2013; Creswell ve Clark, 2014). Araştırmanın nicel bölümünde, okullarda otantik liderliğin motivasyon ve iş doyumu üzerindeki etkisi belirlenmeye çalışılmıştır. Bu araştırma değişkenler arasındaki ilişkileri ve bağlantıları incelediğinden ilişkisel tarama modeli kullanılmıştır. Araştırmanın nitel bölümünde araştırma deseni olarak durum çalışması kullanılmıştır.

\section{Katılımcilar}

Araştırmanın evrenini 2017-2018 akademik yılında Erzurum merkez ilçe okullarında görev yapan devlet okulu öğretmenleri oluşturmaktadır. Araştırmanın evreninde toplam 5040 öğretmen bulunmaktadır. Evrenden araştırmaya dâhil edilecek örneklem büyüklüğünü belirlemek için Cochran'ın örnek boyut formülü kullanılmıştır (Bartlett, Kotrlik, \& Higgins, 2001). Buna göre örneklem büyüklügünün en az 356'dan büyük olması beklenmektedir.

Araştırmanın nicel kısmı için örneklem belirlenirken çok aşamalı örneklem seçilmiştir. Birinci aşamada Erzurum ili merkez ilçeleri evrenini hepsi bir kümeye ait olacak biçimde ve hiç biri açıkta kalmayacak şekilde Yakutiye, Palandöken ve Aziziye olmak üzere üç bölüme ayrılmıştır. İkinci aşamada örnekleme yöntemi olarak “ oranlı küme örnekleme ” yöntemi kullanılmıştır (Karasar, 1998). Bu örneklem elemanların birbirinden dağınık ve uzak olduğu durumlarda uygulanmaktadır. Seçilen gruplar içindeki elemanlar örneklemi oluşturmaktadır yani seçilen bu gruplardan elemanlar seçilir (Arlı \& Nazik, 2004). Çalışma evreni oluşturan her bir ilçedeki okullar küme olarak kabul edilmiştir. Bu kümelerdeki okulların listeleri çıkartılarak ve tesadüfü olarak okullar belirlenmiştir. Üçüncü olarak seçilen okullarda görev yapan yeterli sayıda öğretmene ölçekler uygulanırken basit tesadüfi örnekleme yöntemi kullanılmıştır. Okullardaki öğretmenlerin örnekleme dahil olma durumu şansa bırakılmış ve tesadüfi olarak seçilen öğretmenlere ölçekler uygulanmıştır (Balcı, 
2010). Sonuç olarak araştırmanın katılımcı grubu devlet okullarında görev yapan 649 öğretmenden oluşmaktadır. Rastgele seçilen öğretmenlere ölçekler uygulanmıştır.

Çalışma grubu $310(\%$ 47,8) kadın ve 339 (\% 52,2) erkek olmak üzere toplam 649 öğretmenden oluşmaktadır. Çalışma grubundaki öğretmenlerin eğitim durumları 553'ü (\% 82,1) lisans, 114'ü (\% 17,6) yüksek lisans ve 2'si (\% 0,3) doktora mezunudur. Çalışma grubu mesleki kıdemi 1-10 yıl arasında 400 (\% 61,6), 11-20 yıl arasında 201 (\% 31,0) ve 48 (\% 7,4) 21 yaş ve üzeridir. Araştırmanın nitel kısmı için amaçlı örnekleme yöntemlerinden biri olan maksimum çeşitlilik örneklemesi kullanılmıştır. Amaçlı örneklemin başlıca özelliklerinden birisi araştırma sorularının niteliğine uygun olarak belirli amaçlara göre kullanılmasıdır. $\mathrm{Bu}$ durumda araştırmacı sorulara ilişkin derin bilgiler bulacağını düşünmektedir. Genellikle bireylerden elde edilecek bilginin derinliğine odaklanır (Teddlie \& Tashakkori, 2015).Nitel araştırma $5(\%$ 45,5) kadın ve $6(\%$ 54,5) erkek olmak üzere 11 öğretmenden oluşmaktadır. Verilerin toplanması, verilerin doygunluğa ulaşması ile durdurulmuştur (Creswell, 2013). Çalışma grubundaki öğretmenlerin eğitim durumu, 8'i (\% 72,7) lisans, 3'ü (\% 27,3) lisansüstü mezunudur. Çalışma grubunun mesleki kıdemi 1-10 y1l arasinda $5(\% 27,3)$ ve $11-20$ yıl arasinda 6 dir $(\% 54,5)$.

\section{Veri Toplama Araçları ve Doğrulayıcı Faktör Analizleri}

\section{Otantik Liderlik Ölçeği}

Walumba ve diğerleri tarafından geliştirilen ölçek. (2008) otantik liderlik davranışını ölçmek için kullanılmıştır. Ölçek 4 faktör etrafında toplanan 16 maddeden oluşmaktadır. İlişkilerde şeffaflık alt boyutu beş maddeden oluşmaktadır. Bununla birlikte içselleştirilmiş ahlak anlayışı dört maddeden oluşmaktadır. Bilgiyi dengeli değerlendirme alt boyutu üç madde içermekledir. Son olarak öz farkındalık alt boyutu ise dört maddeden oluşmaktadır. Ölçek ( 1 = Kesinlikle Katılmıyorum; $5=$ Kesinlikle Katılıyorum) beşli Likert tipinde düzenlenmiştir. $\mathrm{Bu}$ ölçek, organizasyondaki otantik liderlik davranışının seviyesini belirlemek için kullanılır. Yapılan hesaplamalara göre, genel otantik liderlik ölçeği için Cronbach Alpha iç tutarlılık katsayısı .928 olarak hesaplanmıştır. Açımlayıcı faktör analizi sonucunda maddelerin madde faktör yükleme aralıkları ,856 ile ,636 arasındadır.

Doğrulayıcı faktör analizi sonucunda 4. ve 5. maddelerin hata oranları modifikasyon indekslerine göre birleştirilmiştir. Doğrulayıcı faktör analizinin uyum değerleri incelendiğinde ölçeğin uyum iyiliği indeksi CMIN / DF $(\mathrm{X} 2 / \mathrm{df})=4.58$; RMSEA = .07; $\mathrm{SRMR}=.0410 ; \mathrm{GFI}=.92 ; \mathrm{AGFI}=.89 ; \mathrm{NFI}=.92 ; \mathrm{CFI}=, 95$ olarak hesaplanmıştır. $\mathrm{Bu}$ 
doğrulayıcı faktör analizi sonucunda elde edilen modelin kabul edilebilir uyum indeksi değerleri içinde kaldığı söylenebilir.

\section{Ögretmen Motivasyon Ölçeği}

Öğretmen motivasyon ölçeği Akan ve Kılıç (2020) geliştirilmiştir. Ölçek 5 faktör etrafında toplanan 18 maddeden oluşmaktadır. Ölçek $(1=$ Kesinlikle Katılmıyorum; $5=$ Kesinlikle Katılıyorum) beşli Likert tipinde düzenlenmiştir. Bu ölçek, okullarda öğretmen motivasyon ölçeğinin düzeyini belirlemek için kullanılmaktadır. Genel otantik liderlik ölçeği için Cronbach Alpha iç tutarlılık katsayısı .889 olarak hesaplanmıştır. Açımlayıcı faktör analizi sonucunda maddelerin madde faktör yükleme aralıkları ,877 ile ,487 arasındadır. Doğrulayıc faktör analizinin uyum değerleri incelendiğinde ölçeğin uyum iyiliği indeksi leri şu şekildedir: CMIN / DF (X2 / df $)=4.06$; RMSEA = .07; SRMR = .0449; GFI = .92; AGFI $=.89 ; \mathrm{NFI}=.93 ; \mathrm{CFI}=, 94 . \mathrm{Bu}$ doğrulayıcı faktör analizi sonucunda elde edilen modelin kabul edilebilir uyum iyiliği indeksi değerleri içinde kaldığı söylenebilir.

\section{İ̧s Doyumu Ölçeği}

İş tatmini ölçeği Weiss, Dawis ve Lofquist (1967) tarafından geliştirilmiştir. Ölçek, iç ve dış doyum olmak üzere iki faktör etrafında gruplandırılmış 20 maddeden oluşmaktadır. Ölçeğin Türkçe adaptasyonu Baycan (1985) tarafindan yapılmıştır. Ölçek $(1=$ Kesinlikle Katılmıyorum; 5 = Kesinlikle Katılıyorum) beşli Likert tipinde düzenlenmiştir. Ölçeğin amacı, çalışanların iş memnuniyetini belirlemektir. Diğer çalışmalar incelendiğinde faktör analizi sırasında birçok maddenin çıkarıldığı görülmüştür. Örneğin, Bil (2018) ölçekten 3 maddeyi çıkarmıştır. Başka bir çalışmada, Tan (2012) 9; Ersözlü (2012) analizden 6 ve Savaş (2012) 8 maddeyi çıkarmıştır. Bu çalışmalar dikkate alındığında, ölçeğin açımlayıcı ve doğrulayıcı faktör analizlerinin yeniden yapılması gerektiği ortaya çıkmıştır.

Analiz sonucunda KMO değeri .925 olarak hesaplanmıştır. Sonuç olarak KMO ve Bartlett testi sonuçlarına göre verilerin faktör analizine uygun olduğu belirlenmiştir $(\mathrm{x} 2=$ $6685,994, \mathrm{df}=190, \mathrm{p}=.000)$. Bu kapsamda 8 madde ölçekten çıkarılmıştır. Dış faktörde yer alan $1,5,13,15,17,18$ ve 19. maddeler ve iç faktördeki 7, 8, 9, 10 ve 11. maddeler kullanılmıştır. Ölçek kapsamında incelenen madde ve faktörlerin toplam varyansın\% 53.725'ini açıkladığı görülmüştür. D1ş boyut için faktörün madde faktör yükleri ,518 ile ,738 arasında değişmektedir. İç doyum ,503 ile ,841 arasındadır. Cronbach Alpha iç tutarlılık katsayısı ölçeğin geneli için .887 olarak hesaplanmıştır. Ölçeğin alt boyutları için hesaplamada, Cronbach Alpha dış boyut için 875; iç boyut için, ise 844. 
Faktör analizine göre 7. ve 10. maddelerin hata oranları modifikasyon indekslerine göre birleştirilmiştir. Ancak, 18. ve 19. maddenin hata oranları birleştirildi. Doğrulayıc1 faktör analizinin uyum değerleri incelendiğinde ölçeğin uyum iyiliği indeksi değerleri CMIN $/ \mathrm{DF}(\mathrm{X} 2 / \mathrm{sd})=4.99 ; \mathrm{RMSEA}=.08 ; \mathrm{SRMR}=0.439 ; \mathrm{GFI}=.94 ; \mathrm{AGFI}=.90 ; \mathrm{NFI}=.92 ;$ $\mathrm{CFI}=$, 93. Bu doğrulayıcı faktör analizi sonucunda elde edilen modelin kabul edilebilir uyum iyiliği indeksi değerleri içinde kaldığı söylenebilir.

\section{Nitel Veri Toplama}

Nitel verilerin toplanmasında görüşme tekniği kullanılmıştır. Görüşme tekniği, katılımcıların duygu, deneyim ve düşüncelerini ortaya koyması açısından oldukça güçlüdür. Görüşmelerde nicel araştırmanın bulguları doğrultusunda araştırmacı tarafından geliştirilen ve üç sorudan oluşan yarı yapılandırılmış görüşme formu kullanılmıştır. Yarı yapılandırılmış görüşmelerin bazı özellikleri şu şekildedir: Yarı yapılandırılmış görüşme formlarında önceden belirlenmiş soru detayları ve ifadeleri bulunmamaktadır. Görüşme genellikle ortaya çıkacak sorulardan oluşur. Katılımcıların her birinden farklı ve özel bilgiler toplanır. Sorular genellikle esnektir (Merriam, 2013).

\section{Veri Analizi}

Katılımcılardan uygulanan ölçekler sonucunda elde edilen verilerin analizinde SPSS ve AMOS programları kullanılmıştır. Ölçeklerin doğrulayıcı faktör analizi ve literatür taraması sonucunda elde edilen modeli test etmek için AMOS programı kullanılmıştır. Uyum incelemesinde model uyumunun değerlendirilmesinde dikkate alınan uyum indeksleri şunlardır: Anlamlılık (p), ki-kare / serbestlik derecesi (X2 / sd = CMIN / DF) ve normlandırılmış uyum indeksleri (NFI), yaklaşık hataların ortalama kare kökü (RMSEA), standardize edilmiş kalıntıların ortalama kare kökü (SRMR), karşılaştırmalı uyum indeksi (CFI), uyum iyiliği indeksi (GFI), düzeltilmiş uyum iyiliği indeksi (AGFI).

Yarı yapılandırılmış görüşme formu ile görüşme sırasında toplanan nitel veriler Microsoft Word programı kullanılarak kayıt altına alınmıştır. Bu veriler Word belgesine kaydedilirken herhangi bir değişiklik yapılmadan aynı şekilde yazılır ve verilerin doğruluğu sürekli kontrol edildi. Bu aşamadan sonra elde edilen veriler NVivo programına aktarıldı. Bir sonraki adımda, bu verileri analiz etmek için içerik analizi kullanılmıştır. Bu okların her birinin kalınlığı, ilgili alt temaya yapılan atıf sayısının beşe bölünmesiyle belirlenir. Başka bir deyişle, bir temaya ve / veya alt temaya maksimum atıf sayısı $5 \mathrm{k}$ olabilirken, en az alıntı $1 \mathrm{k}$ olabilir. 


\section{Bulgular}

\section{Araştırmanın Nicel Kısmına İlişkin Bulgular}

Araştırmanın bu bölümünde nicel kısma ilişskin bulgulara yer verilecektir.

\section{Araştırmanın birinci sorusuna ilişkin bulgular}

Otantik liderlik, motivasyon ve iş doyumu arasındaki ilişkiyi belirlemek üzere yapılan korelasyon analizi sonucunda, otantik liderlik ve iş doyumu $(\mathrm{r}=.539)$ arasında; otantik liderlik ve motivasyon $(\mathrm{r}=.355)$ arasında; motivasyon ve iş doyumu $(\mathrm{r}=.493)$ arasında orta düzeyde pozitif ve anlamlı bir ilişki varlığı ortaya konulmuştur.

Tablo 1. Otantik Liderlik, Motivasyon ve İş Doyumu Arasındaki İlişkiye Yönelik Korelasyon Tablosu

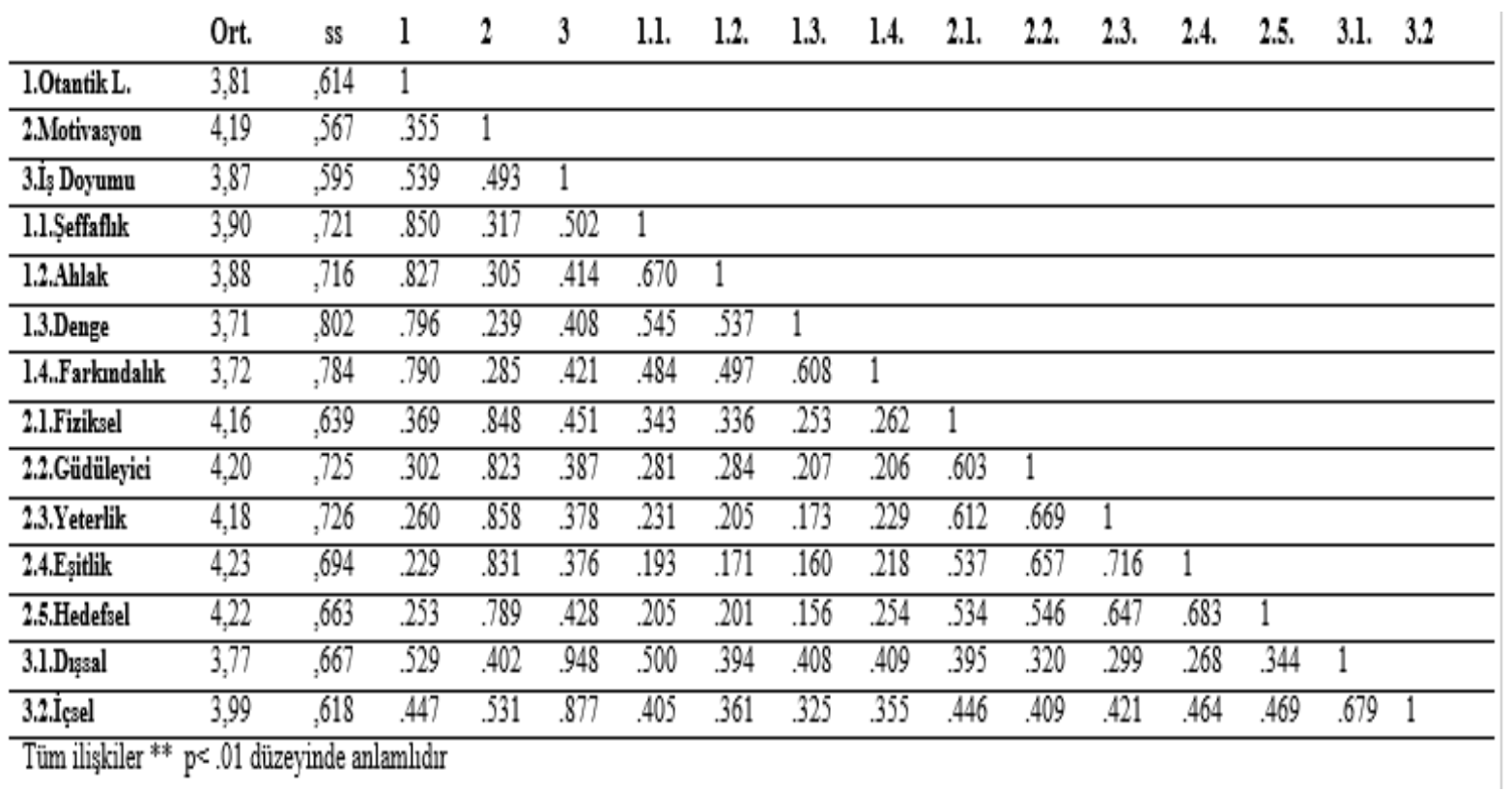

\section{Araştırmanın ikinci, üçüncü, dördüncü ve beşinci sorularına ilişkin bulgular}

Alan yazın taraması sonucunda ortaya çıkan ve otantik liderliğin öğretmenlerin motivasyonu ve iş doyumu üzerindeki etkisini ortaya çıkarmayı amaçlayan teorik model, AMOS programı kullanılarak yapısal bir eşitlik modeli ile incelenmiştir. Otantik liderlik, öğretmen motivasyonu ve iş doyumu arasındaki ilişkiyi açıklamaya yönelik tahminler aşağıdaki şekilde gösterilmektedir. 


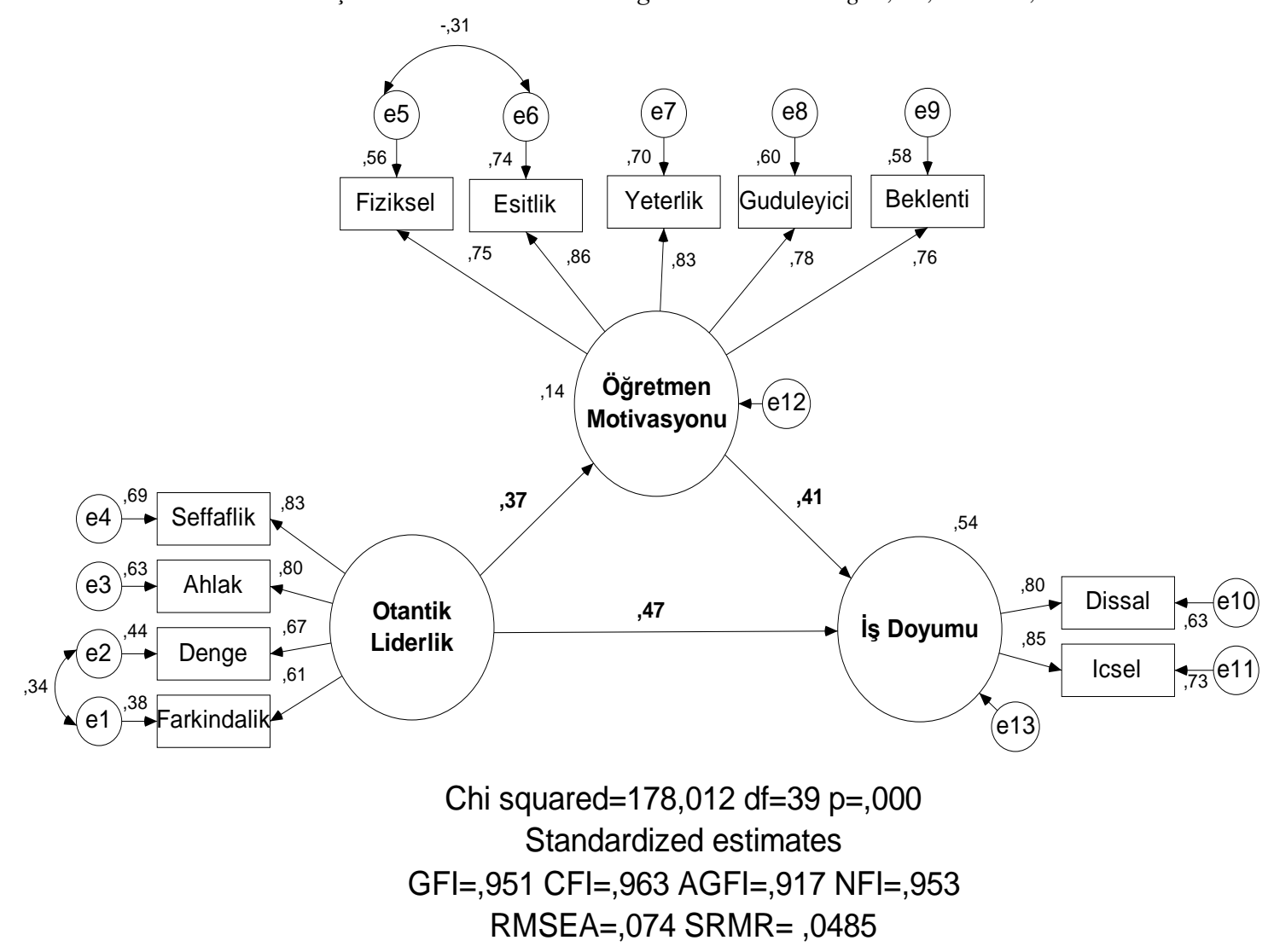

Şekil 1: Yapısal eşitlik modeline ilişkin sonuçlar

Hedef model analizinin uyum değerleri incelendiğinde modelin uyum iyiliği indeksi değerleri CMIN / DF $(\mathrm{X} 2 / \mathrm{sd})=4.56$; $\mathrm{RMSEA}=.074 ; \mathrm{SRMR}=0.485 ; \mathrm{GFI}=.951 ; \mathrm{AGFI}=$ .917 ; NFI $=.953$; CFI =, 963 olarak bulunmuştur. Yapısal eşitlik modelinin uyumu ile ilgili istatistiksel değerler incelendiğinde, model uyum değerlerinin kabul edilebilir değerler içerisinde olduğu ve modelin uyum indeksleri bağlamında kabul edilebilir aralıkta olduğu söylenebilir.

Kİ-Kare uyum testi (X2) uyum iyiliği indeksi içinde bakılan ilk değerdir ve serbestlik derecesi (SD) ile olan oranı bağlamında değerlendirilir. Buna bağlı olarak iyi uyum değerinin X2/SD oranının 5'ten küçük olması kabul edilebilir bir uyum olduğu söylenebilir. $\mathrm{Bu}$ araştırma için $\mathrm{X} 2 / \mathrm{SD}$ değeri 178.01/39=4.56 değeri bulunmuştur. $\mathrm{Bu}$ sonuçlar bağlamında ele alındığında, X2/SD değerinin kabul edilebilir uyumu karşıladığı gözlenmektedir (Meydan \& Şeşen, 2001).

İkinci sırada AGFI, GFI ve SRMR gibi kalıntılara dayalı uyum indeksleri incelenmiştir. Standardize olmuş kalıntı ortalamaların karekökü olan SRMR'nin değerinin ,05'den küçük olması iyi uyum değeri sınırı içinde olduğu söylenebilir. Bu araştırmada SRMR=,0485 olarak iyi uyum gösterdiği gözlenmiştir. Örneklem hacminin artmasıyla 
varyans ve kovaryansı gösteren bir değer olan GFI'nın 0,95 ile 1,00 olması iyi uyum göstermektedir. $\mathrm{Bu}$ araştırmada $\mathrm{GFI}=, 951$ değri olması iyi uyum gösterdiğini ortaya koymuştur. Örneklem hacminin fazlalığını ortaya koyan AGFI=,917 değerini alarak iyi uyum gösterdiği gözlemlenmiştir (Bayram, 2010).

Üçüncü sırada öncelikle küçük örneklem hacimlerinde kararsız olan NFI değeri incelenmiştir. NFI=,953 değeri ile iyi uyum gösterdiği söylenebilir. Diğer taraftan örneklem sayısına duyarlılı̆̆ı ile bilinen $\mathrm{CFI}=, 963$ değeri ile kabul edilebilir değerler sınırında kalmıştır. Son olarak RMSEA=,074 ile kabul edilebilir değerler sınırında kalmıştır (Bayram, 2010; Meydan \& Şeşen, 2001).

Araştırmanın ikinci sorusuyla ilgili olarak, standardize edilmiş regresyon katsayıları incelendiğinde, otantik liderliğin öğretmen motivasyonu üzerinde olumlu ve anlamlı bir etkiye sahip olduğu söylenebilir $(\beta=, 37 ; \mathrm{P}<, 01)$. Bu değer için kritik oran 7.53 ve standart hatası 05'tir. Yani okullarda müdürlerin özgün davranışları arttığında öğretmenlerin motivasyonu artmaktadır.

Araştırmanın üçüncü sorusu bağlamında standardize edilmiş regresyon katsayılarına bakıldığında, öğretmenlerin motivasyonunun iş doyumu üzerinde olumlu ve anlamlı bir etkiye sahip olduğu söylenebilir $(\beta=, 41 ; \mathrm{P}<, 01)$. Bu değer için kritik oran 9.60 ve standart hatası 05'tir. Bu bağlamda öğretmenlerin motivasyonu arttıkça iş doyumlarının da arttığı söylenebilir.

Araştırmanın dördüncü sorusu kapsamında standardize edilen regresyon katsayıları, otantik liderliğin öğretmen iş doyumu üzerinde olumlu ve anlamlı bir etkiye sahip olduğu söylenebilir $(\beta=, 47 ; \mathrm{P}<, 01)$. Bu değer için kritik oran 8.39 ve standart hatası 06 'dır. Bu bulgu 1şığında yöneticilerin özgün davranışları arttıkça iş doyumlarının arttığı söylenebilir.

Bulgular araştırmanın beşinci araştırma sorusu bağlamında incelendiğinde otantik liderlik ve motivasyonun iş doyumunu \% 54 oranında anlamlı olarak açıkladığı görülmüştür. Diğer bir deyişle, iş doyumundaki değişiminin nedeninin \% 54'nün otantik liderlik ve motivasyon kaynaklı olduğu söylenebilir. 


\section{Nitel Araştırmaya İlişskin Bulgular}

Bu bölümde nitel araştırmaya ilişkin bulgular verilmiştir.

\section{Araştırmanın altıncı sorusuna ilişkin bulgular}

Nitel kısım için, katılımcıların öğretmenleri motive eden otantik davranışlara ilişkin görüşlerinden elde edilen şema aşağıdaki şekilde gösterilmiştir. Ayrıca öğretmenleri motive eden otantik davranışlara ilişskin görüşlerden oluşan temalar ve bu temaların ortaya çıkmasına neden olan referans görüşler aşağıda verilmiştir.

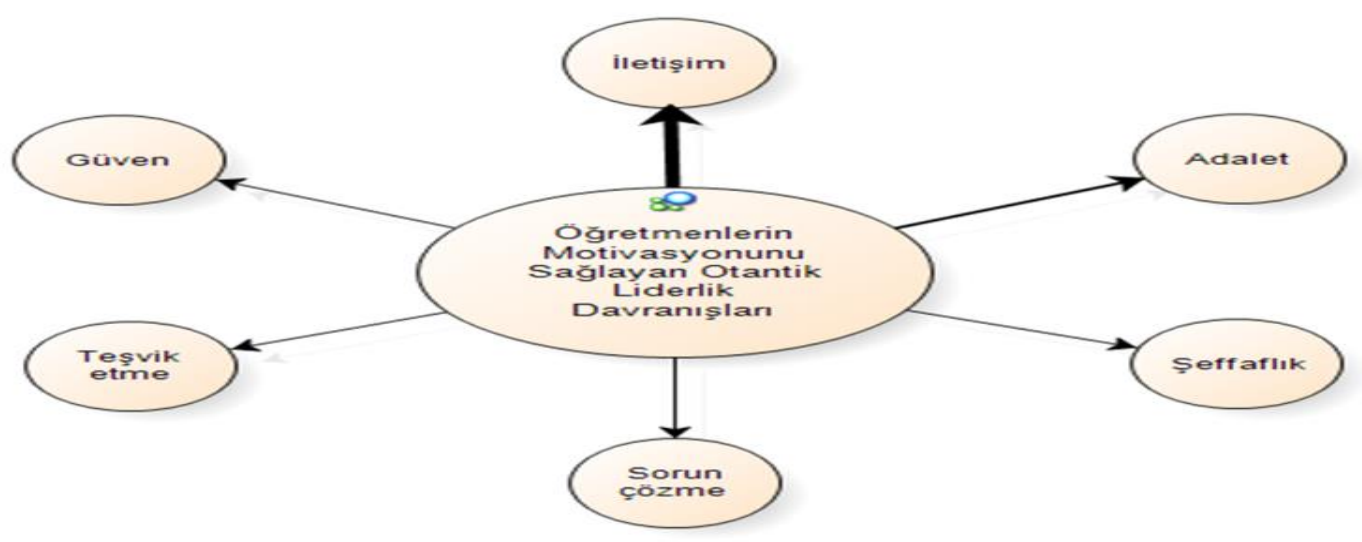

Şekil 2. Öğretmenlerin motivasyonunu sağlayan otantik liderlik davranışları

İletişim: Nitel analizin sonucunda "iletişim" en çok atıf yapılan tema olmuştur. Buna göre öğretmenlerin iletişimlerini etkileyen otantik davranışın olduğuna inandıkları söylenebilir. İletişim alt temasına ilişkin görüşlere ilişkin örnek ifadeler aşağıda verilmiştir.

" ...yönetici ile konuşabilme ve hiç kimseyi ayırmadan öğretmenlerle konuşması oldukça önemlidir...(Ö, 1) "

" ... okul ortamında etkili bir iletişim kurulmasında ve bir hedef belirlenmesi ve bu hedefi gerçekleştirmekte bu tür davranışların oldukça önemlidir ...(Ö, 2) "

" ...örneğin ben beden eğitim öğretmeniyim, iletişim kurabildiğim bir yöneticim var. Bu yüzden bir değil üç takım çalıştırıyorum...(Ö, 4) "

Adalet: Nitel analiz sonucunda öğretmenleri motive eden otantik davranışlardan birisi "adalet" temasıdır. Aşağıda adalet alt temasına örnekler verilmiştir.

"...herkese eşit davranması ve ayrımcılık yapmaması motivasyonu arttırır. Çünkü adaletli davranıldığı sürece kimseye ayrıcalık göstermemiş olur.... (Ö, 6)" 
"... çok nazikti. İnsanlara olan iletişiminde makam ve statüsünün etkisi yoktur. Her öğretmenine adil davranırdı... (Ö, 7)"

Şeffaflık: Nitel analiz sonucunda öğretmenleri motive eden otantik davranışlardan birinin "şeffaflık" olduğu söylenebilir. Şeffaflık alt temasına, "... kurum yöneticinizin sizin yanınızda bir başka personel aleyhine konuşan birine yönelik ben personelim lehinde ya da aleyhinde bir şey konuşulmasını istemem bunu duymak hiç istemem ... (Ö, 11)" görüşü örnek olarak verilebilir.

Sorun Çözme: Nitel analiz sonucunda öğretmenlerin motivasyonunu sağlayan özgün davranışlardan birinin "sorun çözme" olduğu söylenebilir. Problem çözme alt temasına gelince, "...velilerle olan ilişkilerde ivedilikle sorun çözülmesi ve yeni alternatifler bulunması yönünde olumlu tarafları vardır ... (Ö, 3)" bir örnek olabilir.

Teşvik Etme: Öğretmenleri motive eden bir başka otantik davranışın da "teşvik etme" olduğu söylenebilir. Teşvik alt temasıyla ilgili olarak "... müdürümüz bizi mutlu ediyor. Bunun karşılığı vermek için bizde kendimizden fedakârlık ediyoruz. Fazladan ders veriyoruz. Bu okulun başarılı olmasını istiyoruz... (Ö, 8)" örnek olabilir.

Güven: Öğretmenleri motive eden bir başka gerçek davranışın da "güven" olduğu söylenebilir. Güven alt temasına, "... yöneticinin öğretmene güvenmesi oldukça önemli örneğin yaptığımız projelere vb. şeylere katkısı oldukça büyüktür. Bize güvenmesi bizim arkamızda olduğunu hissetmek oldukça önemlidir... (Ö, 8)" fikri örnek verilebilir.

\section{Araştırmanın yedinci sorusuna ilişkin bulgular}

İş doyumunu sağlayan motivasyona ilişkin katılımcı görüşlerinden elde edilen veriler aşağıdaki şekilde gösterilmiştir.

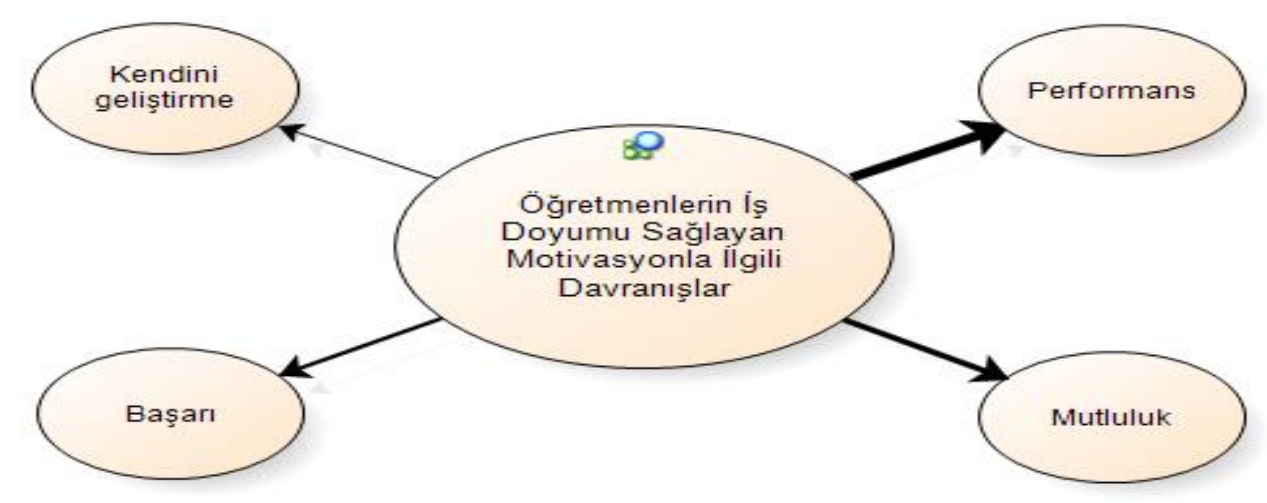

Şekil 3. Öğretmenlerin iş doyumunu sağlayan motivasyonla ilgili davranışlar 
Performans: Nitel analiz sonucunda öğretmenlerin iş doyumunu sağlayan motive edici davranışlar üzerindeki en yüksek yüklemenin "performans" temasına yapılmış olduğu gözlenmektedir. Buna göre öğretmenlerin iş doyumlarını etkileyen motivasyon temelli davranışların ilk sırada performans olduğu söylenebilir. Performans alt temasına ilişkin görüşlere örnekler aşağıda verilmiştir.

"... bazen, bir ders saatinde beş etkinlik yapıyorsunuz. Eğer motivasyonunuz düşükse bir saatinde bir etkinlik yapabiliyorsunuz...(Ö, 4) "

"... motivasyonum yüksek olduğunda başaramayacağım üstesinden gelemeyeceğim hiç bir şey yokmuş gibi hissediyorum, yaşam enerjim yüksek olduğunda da bu öğrencilerime yansıyor onlarda daha verimli ve pozitif oluyorlar...(Ö, 7)"

" ...adil bir iş ortamına sahip olduğumu düşüyorsam, yani sadece iş performansımdan dolayı değerlendireceğimi düşünüyorsam öncelikle motivasyonum ve iş başarım yüksek olur...(Ö, 11) "

Mutluluk: Nitel analiz sonucunda öğretmenlerin iş doyumunu sağlayan bir diğer tema da "mutluluk" dur. Buna göre öğretmenlerin iş doyumlarını en çok etkileyen motivasyon davranışlarından birinin mutluluk olduğuna inandıkları söylenebilir. Aşağıda mutluluk alt temasına ilişkin görüşlere örnekler verilmiştir.

"... eğer işinizden motive değilseniz iş doyumu yaşayamazsınız. Motivasyon olmazsa sonuç ve başarı getirmez...(Ö, 5)"

"... bu iki arasında domino etkisi olduğunu düşünüyorum. Buda sonucunda sizi mutlu ediyor...(Ö, 8)"

Başarı: Nitel analiz sonucunda öğretmenlerin iş doyumunu sağlayan motive edici davranışlara yönelik başka bir yükleme de "başarı" temasına yapılmıştır. Buna göre öğretmenlerin iş doyumlarını en çok etkileyen motivasyonel davranışlardan birinin başarı olduğuna inandıkları söylenebilir. Başarı alt temasıyla ilgili görüş örnekleri aşağıda verilmiştir.

"... bir öğretmen işine motive olmuşsa onu kimse durduramaz. Öğrencilerine yeni ufuklar açabilir ve onların hayatlarında iz bırakabilir. Sınıf ortamında bundan nasibini alır. Öğrencilerdeki pozitif değişme velilere de yansır. Hedeflerimize ulaşmak kaçınılmaz olur... (Ö, 3) " 
Kendini Geliştirme: Öğretmenlerin iş doyumunu sağlayan bir diğer motive edici davranış da "kendini geliştirme" olduğu söylenebilir. Kişisel gelişim alt temasıyla ilgili olarak "... bu olumsuz durumu öğrenciye değil de kendimize atfettiğimizde motivasyonumuz zarar görmektedir. Bu da mesleğini yapmaktan zevk alamayan, kendini geliştiremeyen, yeniliklere açık olmayan öğretmen modelleri karşımıza çıkartmaktadır.... (Ö, 5)” bir örnek olabilir.

İş doyumunu sağlayan otantik davranışlara öğretmenlerin ilgisine ilişkin katılımcı görüşlerinden elde edilen şema şekilde gösterilmiştir. Ayrıca öğretmenlerin iş doyumunu sağlayan özgün davranışlara ilişkin görüşlerinden kaynaklanan temalar ve bu temalara yol açan referans görüşler aşağıda verilmiştir.

\section{Araştırmanın sekizinci sorusuna ilişkin bulgular}

İş doyumunu sağlayan otantik liderlik davranışlarına ilişkin katılımcı görüşlerinden elde edilen veriler aşağıdaki şekilde gösterilmiştir.

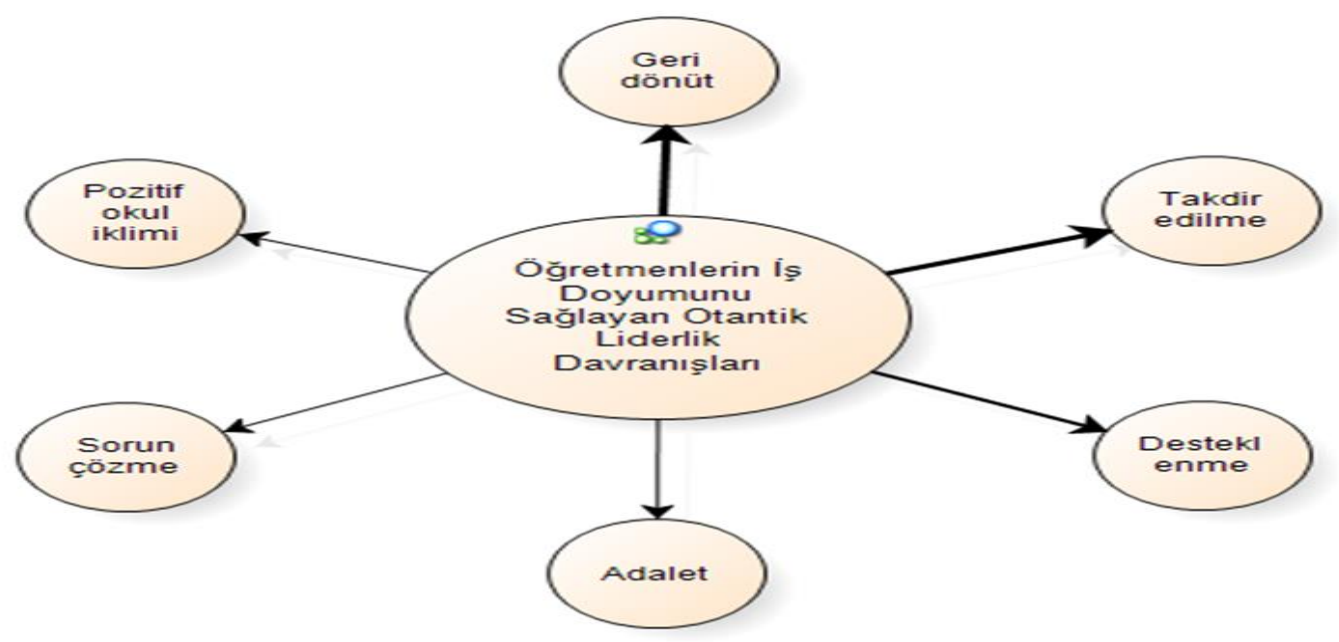

Şekil 4: Öğretmenlerin iş doyumunu sağlayan otantik liderlik davranışları

Geri Dönüt: Nitel analiz sonucunda öğretmenlerin iş doyumunu sağlayan otantik davranışlar üzerine en fazla yüklemenin "geri dönüt" temasına yapıldığı görülmüştür. Buna göre öğretmenlerin iş doyumunu en çok etkileyen özgün davranışlardan birinin dönüt olduğu söylenebilir. Geri dönüt alt temasına ilişkin görüşlere örnekler aşağıda verilmiştir.

"... ayrıca okul yöneticisinin öğretmeninden sadece kendi işi olan işleri yapmayı beklemesi ve sonucunda olumlu dönüt vermesi öğretmenin yaptığı işte iş doyumu kazanmasını sağlar... (Ö, 2)" 
" ... verdiğim emeğe bakılarak değerlendirmek her zaman istediğim şeydir. $\mathrm{Bu}$ iş doyumunun artmasına sebep olur. Ama direk olumsuz açıdan bakıp, olumsuz yönümün eleştirilmesi iş doyumuma olumsuz yönde etkiler...(Ö, 6) "

"... özellikle geri dönüt olmazsa bu iş olmaz. Özellikle yönetim, öğrenci ve öğretmen arkadaşlarımızdan yapıcı eleştiriler alınca iş doyumumuzun artacağı bir gerçektir... $($ Ö, 10)"

Takdir Edilme: Nitel analiz sonucunda öğretmenlerin iş doyumunu sağlayan otantik davranışlar üzerine en çok yüklenen ikincisinin "takdir edilme" teması üzerinde yapıldığı görülmüştür. Buna göre öğretmenlerin iş doyumunu en çok etkileyen otantik davranışlardan birinin takdir olduğu görülmektedir. Aşağıda takdir alt temasına ilişkin görüşlere örnekler verilmiştir.

"...örneğin sözlü olarak takdir edilmek veya başarı belgesi almak çok önemlidir. Takdir edilince işten aldığınız zevk artıyor...(Ö, 4)"

"... yöneticinin ödül mekanizmasından yararlanarak iş doyumunu arttıracağını düşünüyorum... (Ö, 11)"

Desteklenme: Nitel analiz sonucunda öğretmenlerin iş doyumunu sağlayan özgün davranışlar üzerindeki üçüncü en fazla yüklemenin "desteklenme" temasına yapıldığı söylenebilir. Destek alt temasıyla ilgili görüşlere bir örnek aşağıda verilmiştir.

... iş ortamında her türlü etkinlikte desteklendiğini bilmek öğretmene yeni ufuklar açar ve daha başka ne üretebilir? Sorusunu sormaya başlar. Buda eğitim camiasında durağanlığı önleyecek en önemli sorudur... (Ö, 3) "

Adalet: Nitel analiz sonucunda öğretmenlerin iş doyumunu sağlayan otantik davranışlardan birinin "adalet" olduğu söylenebilir. Adalet görüşü alt temasıyla ilgili olarak örnek olabilir "... sadece eşitlik ilkesine göre hareket etmemesi aynı zamanda adaletli olması gerektiğini düşünüyorum. Çalışanla çalışmayanı ayı kefeye koymamalı çalışana pozitif ayrımcılık yapması gerektiğini düşünüyorum. Güler yüzlü ve sevecen olmalı, planl1-programlı olmalı, model olmalı ve sosyal bir karakteri olmalıdır.... (Ö, 7) "

Sorun Çözme: "sorun çözme" nin öğretmenlerin iş doyumunu sağlayan bir diğer otantik davranış olduğu söylenebilir. Problem çözme alt temasıyla ilgili "... okulun dışında bir üst makamda olsa bile sorunumuzun çözülmesi için yardım alabiliyor sorunlarımızın çözümü için destek görüyoruz. Örneğin projeler olduğu zaman yöneticilerimiz problemi kendileri 
çözüyor eğer çözemezlerse bir üst makama bizim için gidiyor ve bize yardımcı olmaya çalışıyorlar. Bu çabayı görünce mutlu oluyorsunuz... (Ö, 7) "görüşü örnek olarak verilebilir.

Pozitif Okul İklimi: Öğretmenlerin iş doyumunu sağlayan bir diğer otantik davranışın da "olumlu okul iklimi" olduğu söylenebilir. Olumlu okul iklimi alt temasıyla ilgili olarak "... idarecinin 1lımlı bir hava oluşturması örneğin size bir günaydın demesi beni yeterince mutlu ediyor. Günaydını duymanız önemli çünkü 2-3 dakika geç kaldığınız zaman size hesap sorulması gerçekten sizi mutsuz ediyor işinizi yaparken bunu yansıtıyorsunuz.... (Ö, 5) " görüşü örnek olabilir.

\section{Tartışma ve Sonuç}

Araştırma sonuçları nicel bağlamda ele alındığında, okul yöneticilerinin otantik liderlik davranışları ile öğretmenlerin motivasyonları arasında pozitif bir ilişki olduğu tespit edilmiştir. Bunun yanısıra, okul yöneticilerinin otantik davranışlarının öğretmenlerin motivasyonu üzerinde olumlu bir etkisi olduğu da ortaya çıkmıştır. Bu sonuçlar aynı zamanda nitel araştırma sonuçlarıyla da desteklenmektedir. Yapılan nitel araştırma sonucunda, otantik liderlik bağlamında okul yöneticilerinin ortaya koyduğu olumlu iletişim, adaletli olma, şeffaflık, problem çözme, öğretmenleri teşvik etme ve güvene yönelik davranışların öğretmenlerin motivasyonunu olumlu etkilediği ortaya çıkmıştır. Özetle, okul yöneticilerinin otantik liderlik bağlamında öz farkındalıkları, bilginin dengeli değerlendirilmesi, içselleştirilmiş bir ahlak anlayışı ve ilişkilerinde şeffaf olmanın öğretmenlerin motivasyonunu olumlu yönde etkilediği düşünülmektedir. $\mathrm{Bu}$ sonuç, yürütülen diğer çalışmaların sonuçlarına benzerdir. Özerten (2018) yaptığı araştırmada okul yöneticilerinin ortaya koydukları otantik liderlik davranışlarının öğretmenlerin motivasyonlarıyla pozitif yönde bir ilişki içinde olduğu ortaya koymuştur. Bununla birlikte öğretmenlerin motivasyonunda olan değişimin sebebinin \%63'nün otantik liderlik kaynaklı belirtmiştir. Okcu ve Anık (2017) benzer şekilde orta düzeyde ve pozitif yönde bir ilişkiye sahip olduklarını ortaya koymuştur. Bunun yanında motivasyondaki değişimin sebebinin \%31'in otantik liderlik kaynaklı olduğunu ortaya koymuştur. Ahmad, Zafar, \& Shahzad (2015) otantik liderlik ile içsel motivasyon arasında orta düzeyde ve anlamlı bir ilişkinin varlığı tespit edilmişlerdir. Aynı çalışmada otantik liderlik motivasyon üstünde pozitif bir etkiye sahip olduğunu belirtmişlerdir (Ahmad, Zafar ve Shahzad, 2015). Bunların dışında literatürde otantik liderlik ve motivasyon arasındaki ilişkiyi ortaya koyan bir çok araştırmaya vardır (Akhlaq ve Ahmed, 2013; Rempel, Holmes ve Zanna, 1985; Guerrero, Lapalme ve 
Seguin, 2015; Shu, 2015; Walumba vd., 2008; Walumbwa vd., 2010; Wong \& Laschinger, 2013).

Okul yöneticilerinin otantik liderlik davranışları ile öğretmenlerin iş doyumu arasında pozitif bir ilişki olduğu tespit edilmiştir. Diğer bir sonuca göre, okul yöneticilerinin otantik davranışlarının öğretmenlerin iş doyumu üzerinde olumlu bir etkisi olduğu ortaya çıkmıştır. Bu iki sonuç, nitel araştırma sonuçlarıyla da desteklenmektedir. Nitel araştırma sonucunda okul yöneticilerinin otantik liderlik bağlamında geribildirim verme, öğretmeni takdir etme, öğretmenleri destekleme, adalet, problem çözme ve pozitif bir okul iklimi oluşturma davranışlarının öğretmenleri olumlu etkilediği ortaya çıkmıştır. Özetle, okul yöneticilerinin özgün liderlik özellikleri bağlamında öz farkındalıkları, dengeli bir bilgi değerlendirmesi, içselleştirilmiş bir ahlak anlayışı ve ilişkilerinde şeffaf olması öğretmenlerin iş doyumunu olumlu etkilemektedir. Okul yöneticilerinin öz farkındalık, dengeli bilgi değerlendirmesi, içselleştirilmiş bir ahlak anlayışı ve ilişkilerinde şeffaflık gibi otantik liderliğin alt boyutlarıyla ilgili davranışlar sergiledikçe öğretmenlerin iş doyumlarının artabileceği söylenebilir. Kılıç ( 2020) yaptığı araştırmada otantik liderliğin iş doyumunu orta düzeyde ve anlamlı olarak etkilediğini ortaya koymuştur. Bununla birlikte, iş doyumunda ortaya gelen değişimin sebebinin \% 78'nin otantik liderlik ve örgütsel adalet kaynaklı olduğunu belirtmiştir. Aydınoğlu (2020) yaptığı araştırmaya göre okul yöneticilerinin otantik liderlik davranışları ile öğretmenlerin iş doyumları arasında orta düzeyde ve pozitif yönde bir ilişki vardır. Bunların dışında, bu araştırmanın sonuçlarının diğer araştırma sonuçlarına benzer olduğu söylenebilir (Anseel ve Lievens, 2007; Azanza, Moriano ve Molero, 2013; Chen, 2008; Penger ve Cerne, 2014; Wong ve Laschinger, 2013). Araştırma sonuçlarına göre öğretmenlerin motivasyonu ile iş doyumu arasında pozitif bir ilişki olduğu, motivasyonlarının iş doyumlarını olumlu etkilediği ortaya çıkmıştır. Bu sonuç, motivasyon bağlamında iş doyumunu etkileyen performans, kendini gerçekleştirme, başarılı ve mutlu hissetme ile nitel araştırma sonucunu desteklemiştir. Bunların dışında bir diğer nicel araştırma sonucu, okul yöneticilerinin otantik liderlik davranışlarının motivasyonla birlikte iş doyumunda değişikliğe neden olmasıdır. Özetle, motivasyonun iş doyumunu etkilediği ve olumlu yönde değişmesinin sebebinin yöneticinin otantik liderlik davranışı ve öğretmenlerin motivasyonlarından kaynaklandığı söylenebilir. $\mathrm{Bu}$ sonuçlar diğer çalışmaların sonuçlarına benzerdir (Brown ve Peterson, 1994; Leroy vd., 2015; Kondalkar, 2007; Tella, Ayeni ve Popoola, 2007; Wong ve Laschinger, 2013). 
Otantik liderlik, öğretmen motivasyonu ve iş doyumu arasında pozitif bir ilişki olduğu bu araştırma kapsamında gözlenmiştir. Bu bulguların hepsi nitel sonuçlarla desteklenmiştir. $\mathrm{Bu}$ bağlamda hizmet içi eğitimlerinde okul yöneticileri ve öğretmenlere bu davranışların birbirleri ile ilişkili olduğunun farkındalığını oluşturmanın genel eğitim politikalarının etkililiği açısından faydalı olacağı düşünülmektedir. Bununa ek olarak, okul yöneticilerinin ortaya koydukları otantik davranışların, öğretmenlerin motivasyonlarıyla birlikte iş doyumu üzerinde pozitif bir değişim yaptığ 1 gözlemlenmiştir. Bu bağlamda, hizmet öncesi ve içi eğitimlerde okul yöneticilerine öz farkındalık sahibi olmaları, ellerindeki bilgiyi doğru değerlendirmeleri, ahlaki ve şeffaf davranışları bir ilke olarak ortaya koymaları durumunda, domino etkisi oluşturarak öğretmenlerin motivasyon ve iş doyumları gibi çok önemli davranışları etkilediklerinin farkındalığının kazandırılması önerilmektedir.

Etik Kurul İzin Bilgisi: Bu araştırma, Erzurum Valiliği İl Milli Eğitim Müdürlüğü’nün 07/09/2018 tarihli 36648235-605.01-E.15801683 sayılı kararı ile alınan izinle yürütülmüştür.

Yazar Çıkar Çatışması Bilgisi: Yazarların beyan edeceği bir çıkar çatışması yoktur.

Yazar Katkısı: Birinci yazar çalışmanın fikrinin oluşturulması, araştırmanın yönteminin belirlenmesi ve makalenin değerlendirilmesi aşamasında katkıda bulunmuştur. İkinci yazar kaynak taraması, verilerin toplanması, verilerin analizi ve makale yazımı konusunda katkıda bulunmuştur. 


\section{Kaynakça}

Ahmad, I., Zafar, M. A., \& Shahzad, K. (2015). Authentic leadership style and academia's creativity in higher education institutions: intrinsic motivation and mood as mediators. Transylvanian Review of Administrative Sciences, 11(46), 5-19.

Akhlaq, A., \& Ahmed, E. (2013). The effect of motivation on trust in the acceptance of internet banking in a low income country. International Journal of Bank Marketing, $31(2), 115-125$.

Alsat, O. Ç. (2016). Çalışan motivasyonunu etkileyen faktörlerin iş tatminine etkisini belirlenmesine yönelik bir uygulama [An application to determine the effects of factors affecting employee motivation on job satisfaction] (Doctoral Dissertation). Higher Education Council Thesis Center (No: 422500)

Anseel, F., \& Lievens, F. (2007). The long term impact of the feedback environment on job satisfaction: A field study in a Belgian context. Applied Psychology, 56(2), 254-266.

Arlı, M., \& Nazik, M. H. (2004). Bilimsel araştırmaya giriş (4. Baskl). Ankara: Gazi Kitabevi.

Avolio, B. J., \& Gardner, W. L. (2005). Authentic leadership development: Getting to the root of positive forms of leadership. The leadership Quarterly,16(3), 315-338.

Aydınoğlu, N. (2020). Yöneticilerin otantik ve paternalist liderlik davranışlarının ögretmenlerin motivasyon, iş tatmini ve örgüt bă̆llliğına etkilerinin incelenmesi [Investigation Of The Effects Of Authentic And Paternalist Leadership Behavior Of Administrators On Teachers'motivation, Job Satisfaction And Organizational Commitment]. İstanbul Gelişim Üniversitesi.

Azanza, G., Moriano, J.A., \& Molero, F. (2013). Authentic leadership and organizational culture as drivers of employees' job satisfaction. Journal of Work and Organizational Psychology 29(2), 45-50.

Balc1, A. (2009). Sosyal bilimlerde araştırma (7. baskı). Ankara: Pegem A Yayıncılık.

Bartlett, J. E., Kotrlik, JW, \& Higgins, CC (2001). Organizational research: Determining appropriate sample size in survey research. Information Technology, Learning, and Performance Journal, 19(1), 43-50.

Barutçugil, İ. (2004). Organizasyonlarda duyguların yönetimi [Managing emotions in organizations]. İstanbul: Kariyer Yayınlar1.

Baycan, A. (1985). An Analysis Of The Several Aspects of Job Satisfaction Between Different Occupational Groups. Boğaziçi Üniversitesi. İstanbul. 
Bayram, N. (2010). Yapısal eşitlik modellemesine giriş AMOS Uygulamaları (2. Bask1).Bursa: Ezgi Kitabevi.

Begley, P. T. (2004). Understanding valuation processes: exploring the linkage between motivation and action. International Studies in Educational Administration, 32(2), 417.

Benson, J. D. (2008). Leadership and Motivation. Research Starters: Business

Bil, E. (2018). Ortaöğretim okullarının öğrenen örgüt, örgütsel güven ve iş doyumu düzeyleri arasındaki ilişki[The relationship between the learning organization, organizational trust and job satisfaction levels of secondary schools] (Doctoral Dissertation). Higher Education Council Thesis Center (No: 494132)

Black, A. E., \& Deci, E. L. (2000). The effects of instructors' autonomy support and students' autonomous motivation on learning organic chemistry: A self-determination theory perspective. Science Education, 84(6), 740-756.

Brown, S. P., \& Peterson, R. A. (1994). The effect of effort on sales performance and job satisfaction. Journal of Marketing, 58(2), 70-80.

Bursalığlu, Z. (2015). Okul yönetiminde yeni yapı ve davranış [The new structure and behavior in school management]. Ankara: Pegem.

Can, Y., \& Soyer, F. (2008). Beden eğitimi öğretmenlerinin sosyo-ekonomik beklentileri ile iş tatmini arasındaki ilişki [The relationship between the socio-economic expectations of physical education teachers and job satisfaction]. Gazi Eğitim Fakültesi Dergisi, 28(1), 61-74.

Chen, L. H. (2008). Job satisfaction among information system (IS) personnel. Computers in Human Behavior, 24(1), 105-118.

Clapp-Smith, R., Vogelgesang, G. R., \& Avey, J. B. (2009). Authentic leadership and positive psychological capital the mediating role of trust at the group level of analysis. Journal of Leadership \& Organizational Studies, 15(3), 227-240.

Colquitt, J. A., Conlon, D. E., Wesson, M. J., Porter, C. O., \& Ng, K. Y. (2001). Justice at the millennium: a meta-analytic review of 25 years of organizational justice research. Journal of Applied Psychology, 86(3), 425-445.

Conlow, R. (1999). Excellence in supervision. Crisp Learning.

Creswell, J. W. (2013). Qualitative, quantitative, and mixed methods approaches. Thousand Oaks, CA: Sage

Creswell, J. W., \& Clark, V. L. P. (2014). Designing and conducting mixed methods research. Sage Publication. 
Creswell, W.J. (2017). A concise introduction to mixed methods research. Sage Publication.

Darvish, H. ve Rezaei, F. (2011) The impact of authentic leadership on job satisfaction and team commitment. Management and Marketing, 6(3):421-436.

Datta, B. (2015). Assessing the effectiveness of authentic leadership. International Journal of Leadership Studies, 9(1), 19-32.

Dinh, J. E., Lord, R. G., Gardner, W. L., Meuser, J. D., Liden, R. C., \& Hu, J. (2014). Leadership theory and research in the new millennium: Current theoretical trends and changing perspectives. The Leadership Quarterly, 25(1), 36-62.

Durdağı, A., \& KILIÇ, M. E. Öğretmen motivasyonu ölçeğinin geliştirilmesi [Development of Teacher Motivation Scale]. Turkish Journal of Educational Studies, 7(2), 16-41.

Dweck, C. S., \& Leggett, E. L. (1988). A social-cognitive approach to motivation and personality. Psychological Review, 95(2), 256-273.

Elliot, A. J., \& Covington, M. V. (2001). Approach and avoidance motivation. Educational Psychology Review, 13(2), 73-92.

Ersözlü, A. (2012). Okul yöneticilerinin yönetsel güçlülük düzeylerinin öğretmenlerin örgütsel bağlllık, örgütsel vatandaşlık davranışlarl ve iş doyumuna etkisi[The effect of school administrators 'managerial strengths on teachers' organizational commitment, organizational citizenship behaviors and job satisfaction] (Doctoral Dissertation). Higher Education Council Thesis Center (No: 422500)

Gardner, W. L., Avolio, B. J., Luthans, F., May, D. R., \& Walumbwa, F. (2005). “Can you see the real me?" A self-based model of authentic leader and follower development. The Leadership Quarterly, 16(3), 343-372.

George, B. \& Sims, P. (2010). True north: Discover your authentic leadership. San Francisco: John Wiley \& Sons.

George, J. M., Jones, G. R., \& Sharbrough, W. C. (1996). Understanding and managing organizational behavior. (3. Edition). Reading, MA: Addison-Wesley.

Giallonardo, L. M., Wong, C. A., \& Iwasiw, C. L. (2010). Authentic leadership of preceptors: predictor of new graduate nurses' work engagement and job satisfaction. Journal of Nursing Management, 18(8), 993-1003

Glynn, M. \& Dejordy, R. (2010). Handbook of leadership theory and practice. N. Nohria\& R. Khurana (Ed.), Leadership trough an organization behavior. Boston: Harvard Business Press. 
Guerrero, S., Lapalme, M. Ė., \& Séguin, M. (2015). Board chair authentic leadership and nonexecutives' motivation and commitment. Journal of Leadership \& Organizational Studies, 22(1), 88-101.

Hellriegel , D., Slocum, J. W., \& Woodman, R. W. (2001). Organization behavior. St. Paul, Minn., West publishing comp. Les Cahiers de la Solidarité.

Henderson, J. E., \& Hoy, W. K. (1982). Leader authenticity: The development and test of an operational measure. Educational and Psychological Research, 3(2), 63 - 75.

Hoy, W. K., \& Miskel, C. G. (1987). Educational administration: Theory, research, and practice. Random House Trade.

Ilies, R., Morgeson, F. P., \& Nahrgang, J. D. (2005). Authentic leadership and eudaemonic well-being: Understanding leader-follower outcomes. The Leadership Quarterly, 16(3), 373-394.

Ilies, R., Morgeson, F. P., \& Nahrgang, J. D. (2005). Authentic leadership and eudaemonic well-being: Understanding leader-follower outcomes. The Leadership Quarterly, 16(3), 373-394.

Isaac, R. Z., Wilfred, J. P., \& Douglas, C. (2001). Leadership and motivation: The effective application of expectancy theory. Journal of Managerial Issues, 13(2), 1045-3695

Karaköse, T., \& Kocabaş, İ. (2006). Özel ve devlet okullarinda öğretmenlerin beklentilerinin 1ş doyumu ve motivasyon üzerine etkileri. Eğitimde Kuram ve Uygulama, 2(1), 3-14.

Karasar, N. (1998). Bilimsel araştırma yöntemi. (8. Baskı). Ankara: Nobel Yayıncılık.

Karataş, S., \& Güleş, H. (2010). İlköğretim okulu öğretmenlerinin iş tatmini ile örgütsel bağlılı̆̆ı arasındaki ilişki. Uşak Üniversitesi Sosyal Bilimler Dergisi, 3(2), 74-89.

Kernis, M. H. (2003). Toward a conceptualization of optimal self-esteem. Psychological Inquiry, 14(1), 1-26.

Kılıç, M. Y. (2020). Otantik Liderlik Davranışlarının, Örgütsel Adalet ve Öğretmenlerin İş Tatmini Üzerine Etkisinin İncelenmesi. [Examining the Effect of Authentic Leadership Behaviors on Organizational Justice and Teachers' Job Satisfaction]. Kastamonu Eğitim Dergisi, 28(6), 2271-2283.

Kundak, Z., Hanife, Üzel., Keleş, A., \& Eğicioğlu, H. (2015). Bir üniversite hastanesinde hemşirelik mesleğinde iş tatmini ve motivasyon[Job satisfaction and motivation in the nursing profession in a university hospital]. Kocatepe T1p Dergisi, 16(1), 1-10.

Lawler, E. E. (1973). Motivation in work organizations. Monterey, CA: Brooks. 
Leroy, H., Anseel, F., Gardner, W. L., \& Sels, L. (2015). Authentic leadership, authentic followership, basic need satisfaction, and work role performance: A cross-level study. Journal of Management, 41(6), 1677-1697.

Locke, E.A. (1976), “The nature and causes of job satisfaction”, in Dunnette, M.D. (Ed.), Handbook of Industrial and Organizational Psychology, Rand McNally, Chicago, IL, pp. 1297-349

Luthans, F., Norman, S., \& Hughes, L. (2006). Authentic leadership: A new approach for a new time. In Inspiring leaders. London: Routledge, Taylor \& Francis.

Madenoğlu, C., Uysal, Ş., Sarıer, Y., \& Banoğlu, K. (2014). Okul müdürlerinin etik liderlik davranışları ile öğretmenlerin iş doyumlarının örgütsel bağlılıkla ilişkisi. Kuram ve Uygulamada Egitim Yönetimi Dergisi, 20(1), 47-69.

Maslow, A. H., Frager, R., \& Fadiman, J. (1970). Motivation and personality (Vol. 2, pp. 1887-1904). New York: Harper Bothers.

McNeese-Smith, D. K. (1997). The influence of manager behavior on nurses' job satisfaction, productivity, and commitment. Journal of Nursing Administration, 27(9), 47-55.

Merriam, S. B. (2013). Introduction to qualitative research. Qualitative research in practice: Examples for discussion and analysis, 1(1), 1-17.

Meydan, H. C. \& Şeşen, H. (2011). Yapısal eşitlik modellemesi Amos Uygulaması. (1. Bask1). Ankara : Detay Yayıncılık.

Okcu, V. \& Anık, S.( 2017). Okul Yöneticilerinin Otantik Liderlik Davranışları İle Öğretmenlerin Motivasyon ve Mobbing (Yıldırma) Yaşama Düzeyleri Arasındaki İlişkilerin İncelenmesi. Anadolu Ĕgitim Liderliği ve Öğretim Dergisi, 5(2), 63-85.

Özerten, K. N. (2018). Okul yöneticilerinin algllanan otantik liderlik özelliklerinin ögretmenlerin mesleki motivasyonuna etkisi (Master's thesis, İstanbul Sabahattin Zaim Üniversitesi, Sosyal Bilimler Enstitüsü, Eğitim Bilimleri Anabilim Dalı).

Penger, S., \& Černe, M. (2014). Authentic leadership, employees' job satisfaction, and work engagement: A hierarchical linear modelling approach. Economic researchEkonomska istraživanja, 27(1), 508-526.

Rempel, J. K., Holmes, J. G., \& Zanna, M. P. (1985). Trust in close relationships. Journal of Personality and Social Psychology, 49(1), 95.-112.

Robbins, S. P., \& Judge, T. A. (2015). Organizational behaviour. New Jersey: Pearson Prentice Hall 
Robbins, S. P., DeCenzo, D. A., \& Coulter, M. K. (2008). Fundamentals of management: essential concepts and applications. Upper Saddle River, NJ: Pearson Prentice Hall.

Savaş, A. C. (2012). Okul müdürlerinin duygusal zekâ ve vduygusal emek yeterliklerinin, öğretmenlerin iş doyumu düzeylerine etkisi [The effect of school principals 'emotional intelligence and $\mathrm{v}$ emotional labor competencies on teachers' job satisfaction levels ] (Doctoral Dissertation). Higher Education Council Thesis Center. ( No: 320035)

Serinkan, C. (2008). Liderlik ve motivasyon geleneksel ve güncel yaklaşımlar [Leadership and motivation traditional and current approaches]. Ankara: Nobel Yayıncılık.

Shamir, B., \& Eilam, G. (2005). "What's your story?” A life-stories approach to authentic leadership development. The Leadership Quarterly, 16(3), 395-417.

Shu, C. Y. (2015). The impact of intrinsic motivation on the effectiveness of leadership style towards on work engagement. Contemporary Management Research, 11(4).

Şimşek, M. Ş., Çelik, A., \& Akgemci, T. (2014). Davranış bilimlerine giriş ve örgütlerde davranış [Introduction to behavioral science and behavior in organizations]. Konya: Eğitim Kitabevi.

Tan, Ç. (2012). İlköğretim okul yöneticilerinin takım liderlik davranışlarının öğretmenlerin iş doyumu, örgütsel adanmışlık ve örgütsel vatandaşlık düzeylerine etkisi [The effect of primary school administrators 'team leadership behaviors on teachers' job satisfaction, organizational commitment and organizational citizenship levels](Doctoral Dissertation). Higher Education Council Thesis Center. (No: 4300428)

Teddlie, C., \& Tashakkori, A. (2015). Karma yöntem araştırmalarının temelleri (T. Dede, \& S. B. Demir, Çev. Ed. ) Ankara: Anı Publishing.

Tella, A., Ayeni, C. O., \& Popoola, S. O. (2007). Work motivation, job satisfaction, and organisational commitment of library personnel in academic and research libraries in Oyo State, Nigeria. Library Philosophy and Practice, 9(2), 3-13.

Toker, B. (2007). Konaklama İşletmelerinde İş Doyumu: Demografik Değişkenlerin İş Doyumu Faktörlerine Etkisi Üzerine Bir Çalışma. Journal of Yasar University, 2(6), 591-615.

Walumbwa, F. O., Avolio, B. J., Gardner, W. L., Wernsing, T. S., \& Peterson, S. J. (2008). Authentic leadership: Development and validation of a theory-based measure. Journal of Management, 34(1), 89-126. 
Walumbwa, F. O., Christensen, A. L., \& Hailey, F. (2011). Authentic leadership and the knowledge economy: Sustaining motivation and trust among knowledge workers. Organizational Dynamics, 40(2), 110-118.

Walumbwa, F. O., Luthans, F., Avey, J. B., \& Oke, A. (2011). Retracted: Authentically leading groups: The mediating role of collective psychological capital and trust. Journal of Organizational Behavior, 32(1), 4-24.

Walumbwa, F. O., Wang, P., Wang, H., Schaubroeck, J., \& Avolio, B. J. (2010). Psychological processes linking authentic leadership to follower behaviors. The Leadership Quarterly, 21(5), 901-914.

Weiss, D. J., Dawis, R. V., England, G. W., \& Lofquist, L. H. (1967). Manual for the Minnesota Satisfaction Questionnaire: Minnesota studies in vocational rehabilitation. Minneapolis: Industrial Relations Center, University of Minnesota.

Wernsing, T. (2018). Leader Self-Awareness and Follower Psychological Empowerment Across Cultures. In Authentic Leadership and Followership. London: Palgrave Macmillan.

Wong, C. A., \& Cummings, G. G. (2009). The influence of authentic leadership behaviors on trust and work outcomes of health care staff. Journal of Leadership Studies, 3(2), 6-23.

Wong, C. A., \& Laschinger, H. K. (2013). Authentic leadership, performance, and job satisfaction: the mediating role of empowerment. Journal of Advanced Nursing, 69(4), 947-959.

Wong, C. A., Laschinger, H. K., \& Cummings, G. G. (2010). Authentic leadership and nurses' voice behaviour and perceptions of care quality. Journal of Nursing Management, 18(8), 889-900.

Yazıcıoğlu, İ. (2010). Örgütlerde iş tatmini ve işgören performansı ilişkisi: Türkiye ve Kazakistan karşılaştırması. Bilig Türk Dünyası Sosyal Bilimler Dergisi,55(1), 243264.

Yıldırım, İ., Akan, D., \& Yalçın, S. (2017). Sınıf öğretmenlerinin iş doyumu ve okul etkililiği algıları arasındaki ilişki. Erzincan Üniversitesi Eğitim Fakültesi Dergisi, 19(1), 69-81.

Yılmaz, A., \& Ceylan, Ç. B. (2011). İlköğretim okul yöneticilerinin liderlik davranış düzeyleri ile öğretmenlerin iş doyumu ilişkisi. Kuram ve Uygulamada Egitim Yönetimi Dergisi, 17(2), 277-394. 
Yılmaz, E., \& Aslan, H. (2013). Öğretmenlerin iş yerinde yalnızlıkları ve yaşam doyumları arasındaki ilişkinin incelenmesi. Pegem Ĕ̆itim ve Öğretim Dergisi, 3(3), 59-69.

Zamahani, M., Ghorbani, V., \& Rezaei, F. (2011). Impact of authentic leadership and psychological capital on followers' trust and performance. Australian Journal of Basic and Applied Sciences, 5(12), 658-667.

Zel, U. (2011). Kişilik ve liderlik: evrensel boyutlarıyla yönetsel açıdan araştırmalar, teoriler ve yorumlar[Personality and leadership: managerial research, theories and interpretations with universal dimensions]. Ankara: Nobel Yayın Dağıtım. 


\title{
Investigation of the Relationship among Authentic Leadership of School Administrators, Teachers' Motivation, and Job Satisfaction * \\ Durdağ $\mathrm{AKAN}^{* *}$ Muhammet Emre KILIÇ${ }^{* * *}$
}

• Received: 17.12.2020 • Accepted: 29.04.2021 • Online First: 29.04.2021

\begin{abstract}
This study aims to determine the effect of authentic leadership on teachers' motivation and job satisfaction in schools. In this study, a mixed-methods sequential explanatory design was conducted. The relational screening model was used in the quantitative part of the study and the case study in the qualitative part. The quantitative part of the study was conducted with 649 school teachers, and the qualitative part was conducted with 11 school teachers. According to the research findings, there is a moderate positive and significant relationship between authentic leadership, motivation, and job satisfaction. It was revealed that authentic leadership and motivation together explained job satisfaction. In addition, communication, justice, transparency, problem-solving, encouragement, and trust are authentic leadership behaviors that provide teacher motivation. According to the study, performance, success, happiness, and self-improvement motivate job satisfaction. According to the research, feedback, appreciation, support, justice, problem-solving, and a positive school climate are authentic leadership behaviors that provide job satisfaction.
\end{abstract}

Keywords: Schools, management, organizational behavior

\section{Cited:}

Akan, D., \& Kilıç, M.E. (2021). Investigation of the relationship among authentic leadership of school administrators, teachers' motivation, and job satisfaction. Pamukkale University Journal of Education, 53, 429-456.doi:10.9779.pauefd.842311

\footnotetext{
* This study is the part of doctoral dissertation of the second author.

** Assoc. Prof. Dr., Atatürk University Department of Educational Administration, ORCID ID: 0000-0002-5397-8470, durdagiakan@atauni.edu.tr

*** Teacher, Aydın Doğan Primary School, ORCID ID: 0000-0001-5511-8573, muhammetemrekilic25@ gmail.com
} 


\section{Introduction}

The school is directly or indirectly affected by the positive and negative experiences of society and individuals. For this reason, schools need positive managerial behaviors in order to solve differentiated and ongoing problems. Teachers' job satisfaction and motivation can give significant clues about the manager's effectiveness in this sense. It is thought the administrators' fair, impartial, transparent, and self-aware actions can be an important solution source for educational institutions' ongoing and current problems.

It can be said that leadership is the behavior of influencing a cluster or group to achieve the organization's goals. Especially, it should be considered an organizational necessity for school administrators to establish a balance between the goals of the school and the needs of the employees (Bursalığlu, 1994; Conlow, 1999; Glynn \& Dejordy, 2010; Robbins, 1998; Zel, 2011). It can be said that some elements that structure leadership are features such as honesty, character, reliability, and respectability (Barutçugil, 2014). In other words, one of the observed behaviors in influencing followers' behaviors is value-based leadership theories. Dinh et al. (2014) explained that value-based leadership theories are authentic leadership, ethical leadership, servant and spiritual leadership behaviors. It is thought that authentic leadership behaviors will positively affect teachers in many ways.

Authentic leaders are people who know themselves (Ilies, Nahrgang, \& Morgeson, 2005). They have an internalized moral understanding and values (George \& Sims, 2010; Walumbwa, Avolio, Gardner, Wernsing, \& Peterson, 2008). They include qualities such as being transparent in their relationships, having a reliable personality, being disciplined, having unique behaviors, sensitive, being a model for employees, and supporting their work (Begley, 2004; Gardner, Avolio, Luthans, May, \& Walumbwa, 2005; Shamir \& Eilam, 2005).

When the studies dealing with the dimensions of authentic leadership are examined at a historical level, it is seen that Kernis (2003) first discussed the dimensions of authentic leadership as awareness, impartial assessment, behavior, and relational authenticity. Another conceptual framework created based on the model made by Kernis (2003) is made by Ilies, Morgeson \& Nahrgang (2005). In this classification, Ilies et al. (2005) classified the dimensions of authentic leadership as self-awareness, balanced assessment, authentic behavior, and authentic relational orientation. When the literature is examined, it is seen that the theoretical infrastructure set forth by Walumbwa et al. Walumbwa et al. (2008) revealed 
the dimensions of authentic leadership as transparency in relationships, internalized moral understanding, self-awareness, and balanced evaluation.

Avolio \& Gardner (2005) revealed the elements of authentic leadership in their research. These elements, respectively; positive psychological capital, moral perspective, leader's self-consciousness, self-regulation, follower's self-consciousness, performance, and development. Related to this, Luthans, Norman, \& Hughes (2006) classify the dimensions of authentic leadership as self-awareness, self-control, balanced evaluation, rational transparency, and authentic behavior.

Studies show that authentic leadership is associated with many organizational outcomes, including job performance, organizational commitment, and job satisfaction (Clapp, Vogelgesang, \& Avey, 2009; Giallonardo, Wong, \& Iwasiw, 2010; Walumbwa et al., 2008; Walumbwa, Wang, Wang, Schaubroeck, \& Avolio, 2010; Walumbwa et al., 2011; Wong, Laschınger, \& Cummings, 2010; Zamahani, Ghorbani, \& Rezaei, 2011). It is thought that authentic leadership positively affects many variables, such as teachers' motivation and job satisfaction. In other words, authentic leadership is thought to affect motivation.

Motivation defines why behaviors occur and people's needs. In other words, it can be said that motivation is the attitude of a person towards behavior or the explanation of why he repeats this behavior (Elliot \& Covington, 2001). Motivation is called the situation that stimulates behavior. Motivation is generally described as an internal process that activates and directs the individual (George, Jones, \& Sharbrough, 1996; Hoy \& Miskel, 2010). When the concept of motivation is examined, it is seen that it is primarily related to many issues such as personality, organization, learning, and performance (Black \& Deci, 2000; Dweck \& Leggett, 1988; Lawler, 1973; Maslow, Frager, \& Cox, 1970). When the literature is examined, it has been observed that authentic leadership positively affects motivation. In addition, authentic leadership is thought to affect job satisfaction.

Job satisfaction can be defined as the emotional state of a person as a result of evaluating their job or work experience (Locke, 1976) or the employee's satisfaction and thoughts about his job (Colquitt, Lepine, \& Wesson, 2009; Hellriegel, 2001; Robbins \& Judge, 2015). When the studies conducted are examined, it has been revealed that job satisfaction is related to age, education, socio-economic status, and professional satisfaction (Can \& Soyer, 2008; Toker, 2007).). In summary, job satisfaction is an individual's general attitude towards his job (Robbins, DeCenzo, \& Coulter, 2008). 
The fact that teachers' high level of job satisfaction is, directly and indirectly, effective in their performance reveals the importance of job satisfaction for teachers (Yazıcıoğlu, 2010; Yıldırım, Akan, \& Yalçın, 2017). First, it is known that factors affecting teachers' job satisfaction are future anxiety, success, and being beneficial to others (Karataş \& Güleş, 2010). It is known that value-based managerial behaviors such as ethical leadership positively affect teachers' job satisfaction (Madenoğlu, Uysal, Sarıer, \& Banoğlu, 2014; Y1lmaz, \& Ceylan, 2011). Accordingly, it is known that the job satisfaction of teachers working in private education institutions is more positively affected by the behavior of their administrators than teachers working in public schools (Karaköse \& Kocabaş, 2006).

Many studies have revealed that leadership and motivation are related (Benson, 2008; Isaac, Zerbe, \& Pitt, 2001). In addition to having a strong relationship between motivation and leadership, it can be said that motivation is very important for increasing productivity in organizations (Serinkan, 2008; Y1lmazer, 2013). Studies have demonstrated that authentic leadership is related to issues affecting motivation such as empowerment of employees, sense of collaboration, and burnout (Henderson \& Hoy, 1982; Walumba et al., 2008; Wong \& Cummings, 2009). Organizations seeking to increase employee motivation in the workplace may wish to encourage authentic leadership and follow-up development in their employees. Although there are many ways to increase employee motivation in the workplace, leadership development is a powerful tool for organizations. Authentic leadership practices are seen as a way to empower employees in organizations (Wernsing, 2018).

It is emphasized that authentic leadership affects work outcomes and performance. In other words, it is observed that leadership behavior positively affects many behaviors of employees, such as job satisfaction. Wong \& Cummings (2009). Authentic leadership emphasizes the key role of authentic leaders in promoting follower development by discovering new skills, autonomy, competence, and job satisfaction (Wong \& Laschinger, 2013). Many studies show that job satisfaction is positively affected by authentic leadership behavior (Darvish \& Rezaei, 2011; Datta, 2015; Wong \& Laschinger, 2013). In addition, it has been observed that authentic leadership has a positive relationship with performance and job satisfaction (Giallonardo, Wong, \& Iwasiw, 2010; Wong \& Laschinger, 2013). McNeese-Smith (1997) found that managers 'behaviors affect employees' job satisfaction, productivity, and commitment. Studies have revealed that authentic leadership, directly and indirectly, affects employees' job satisfaction, and there is a relationship between them 
(Giallonardo, Wong, \& Iwasiw, 2010; Azanza, Moriano \& Molero, 2013; Wong \& Laschinger, 2013). In summary, it is thought that authentic leadership behavior positively affects job satisfaction in schools.

It is important to understand what motivates the members of the organization. In this way, it will be easier for them to be motivated. The factors that affect both motivation and job satisfaction are quite high. When considered in this context, it can be said that one of the keys to ensuring job satisfaction is motivation. There is a reciprocal relationship between motivation and job satisfaction. An individual with job satisfaction can be motivated. Likewise, motivated individuals will be happy with their job. As a result, motivation can create job satisfaction. If the individual achieves what he wants to get from his job, he will have job satisfaction. (Alsat, 2016; Kundak, Üzel, Keleş \& Eğicioğlu, 2015; Şimşek, Çelik \& Akgemci, 2008). As a result of the literature review, it can be said that administrators 'authentic leadership behaviors positively affect teachers' motivation and job satisfaction.

\section{The Aim of the Study}

This study aims to determine the effect of authentic leadership on teachers' motivation and job satisfaction. In order to determine the effect of authentic leadership behaviors of educational administrators on teachers' motivation and job satisfaction, this model will be supported with qualitative research. The quantitative and qualitative research questions developed to achieve this general purpose of the study are presented below.

\section{Quantitative research questions}

Q1. Is there a relationship between authentic leadership and teachers' motivation and job satisfaction?

Q2. What direction and level does authentic leadership affect teachers' motivation?

Q3. what direction and level does the motivation of teachers affect their job satisfaction?

Q4 what direction and level does authentic leadership affect teachers' job satisfaction?

Q5. Does teachers' motivation, together with authentic leadership, explain the change in job satisfaction meaningfully?

\section{Qualitative research questions}

Q6. What do teachers think about authentic leadership behaviors that affect their motivation? 
Q7. What do teachers think about their motivation to affect their job satisfaction?

Q8. What do teachers think about authentic leadership behaviors that affect their job satisfaction?

\section{Method}

In this study, a mixed-method exploratory sequential design was used. This method is called sequential since the quantitative phase is followed by a qualitative phase (Creswell, 2013; Creswell \& Clark, 2014). In the quantitative part of the study, the effect of authentic leadership in schools on motivation and job satisfaction was determined. Since this research examines the relationships and connections between variables, a relational scanning model was used. In the qualitative part of the research, the case study was used as the research design.

\section{Participants}

The research universe consists of the state school teachers working in Erzurum central district schools in the 2017-2018 academic year. There are a total of 5040 teachers in the universe of the research. Cochran's sample size formula was used to determine the sample size to be included in the study from the universe (Bartlett, Kotrlik, \& Higgins, 2001). Accordingly, the sample size is expected to be at least over 356.

While determining the sample for the quantitative part of the study, a multi-stage sample was chosen. In the first stage, the central districts of Erzurum were divided into three parts, namely Yakutiye, Palandöken, and Aziziye, all of which belong to a cluster and none of them remain uncovered. In the second stage, the "proportional cluster sampling" method was used as the sampling method (Karasar, 1998). This sample is applied in situations where elements are dispersed and distant from each other. Elements in the selected groups constitute the sample. Members of these selected groups are selected (Arl1 \& Nazik, 2004). Schools in each district that make up the universe of the study are accepted as a cluster. The lists of the schools in these clusters were removed, and the schools were determined randomly. Thirdly, the simple random sampling method was used while applying the scales to a sufficient number of teachers working in the selected schools. The inclusion of teachers in the sampling at schools was left to chance, and scales were applied to randomly selected teachers (Balc1, 2010). As a result, the participant group of the research consists of 649 teachers working in public schools. Scales were applied to randomly selected teachers. 
A simple random sampling method was used for the quantitative part of the study. The study group consists of 649 teachers, 310 (47.8\%) female and 339 (52.2\%) male. The educational status of the teachers in the study group, $553(82.1 \%)$ was undergraduates, 114 $(17.6 \%)$ were graduate, and $2(0.3 \%)$ were Ph.D. graduates. Working group professional seniority is $400(61.6 \%)$ between 1-10 years, 201 (31.0\%) between 11-20 years, and 48 (7.4\%) 21 years and above. For the qualitative part of the study, one of the purposeful sampling methods, maximum diversity sampling, was used. One of the main characteristics of purposeful sampling is that it is used for specific purposes by the nature of research questions. In this case, the researcher thinks that he will find in-depth information about the questions. It generally focuses on the depth of the information obtained from individuals (Teddlie \& Tashakkori, 2015). Qualitative research consists of 11 teachers, 5 (45.5\%) female and $6(54.5 \%)$ male. Data collection was stopped when the data reached saturation (Creswell, 2013). The educational status of the teachers in the study group, 8 (72.7\%) were undergraduates, and $3(27.3 \%)$ were graduate graduates. The working group's professional seniority is $5(27.3 \%)$ between $1-10$ years and $6(54.5 \%)$ between $11-20$ years.

\section{Data Collection instruments and Confirmatory factor analyses}

\section{Authentic leadership scale}

The scale developed by Walumba et al. (2008) was used to measure authentic leadership behavior. The scale consists of 16 items gathered around four factors. The transparency subdimension consists of five items. However, moral consists of four items. The balance subdimension includes three items. Finally, the self-awareness sub-dimension consists of four items. The scale ( $1=$ Strongly Disagree; $5=$ Strongly Agree) is arranged in a five-point Likert type. This scale is used to determine the level of authentic leadership behavior in the organization. According to the calculations, the Cronbach Alpha internal consistency coefficient for the overall authentic leadership scale was 928. As a result of the exploratory factor analysis, the item factor loading ranges are between .856 and .636 .

As a result of the confirmatory factor analysis, the error rates of the 4th and fifth items were combined according to the modification indices. When the fit values of the confirmatory factor analysis were examined, the goodness of fit index of the scale was $\mathrm{CMIN} / \mathrm{DF}(\mathrm{X} 2 /$ d.f $)=4.58 ; \mathrm{RMSEA}=.07 ; \mathrm{SRMR}=.0410 ; \mathrm{GFI}=.92 ; \mathrm{AGFI}=.89 ; \mathrm{NFI}=$ .92; CFI =, calculated as 95. It can be said that the model obtained as a result of this confirmatory factor analysis remained within acceptable goodness of fit index values. 


\section{Teacher motivation scale}

The teacher motivation scale was developed by Akan and Kılıç ( 2020). The scale consists of 18 items gathered around five factors. The scale $(1=$ Strongly Disagree; $5=$ Strongly Agree) is arranged in a five-point Likert type. This scale is used to determine the level of teacher motivation scale in the schools. The Cronbach Alpha internal consistency coefficient for the overall authentic leadership scale was calculated as 889. As a result of the exploratory factor analysis, the item factor loading ranges are between .877 and .487 . When the fit values of the confirmatory factor analysis were examined, the goodness of fit index of the scale was calculated as CMIN / DF $(\mathrm{X} 2 /$ d.f $)=4.06 ; \mathrm{RMSEA}=.07 ; \mathrm{SRMR}=.0449$; $\mathrm{GFI}=.92 ; \mathrm{AGFI}=.89 ; \mathrm{NFI}=.93 ; \mathrm{CFI}=, 94$. It can be said that the model obtained as a result of this confirmatory factor analysis remained within acceptable goodness of fit index values.

\section{Job satisfaction scale}

The job satisfaction scale was developed by Weiss, Dawis, \& Lofquist (1967). The scale consists of 20 items grouped around two factors called internal and external satisfaction. Baycan (1985) has translated the scale to Turkish. The scale $(1=$ Strongly Disagree; $5=$ Strongly Agree) is arranged in a five-point Likert type. The purpose of the scale is to determine the job satisfaction of the employees. When other studies were examined, it was observed that many items were removed during factor analysis. For example, Bil (2018) removed three items from the scale. In other studies, Tan (2012) removed 9, Ersözlü (2012) removed six, and Savaş (2012) 8 items from the analysis. These findings revealed that the exploratory and confirmatory factor analyzes of the scale should be re-performed.

As a result of the analysis, the KMO value was calculated to be 925. As a result, $\mathrm{KMO}$ and Bartlett test results determined that the data were suitable for factor analysis $(\mathrm{x} 2=$ $6685,994, \mathrm{df}=190, \mathrm{p}=.000)$. In this context, eight items were removed from the scale. Items $1,5,13,15,17,18$, and 19 in the external factor and items 7, 8, 9, 10, and 11 in the internal factor were gathered. It was observed that the items and factors analyzed within the scope of the scale explained $53.725 \%$ of the total variance. For the external dimension, the item factor loadings of the factor vary between 518 and 738. The internal satisfaction is between 503 and 841. The Cronbach Alpha internal consistency coefficient was calculated as 887 for the overall scale. In the calculation for the sub-dimensions of the scale, for external of the Cronbach Alpha, internal consistency is .875; for the internal is, .844 . 
According to factor analysis, the error rates of the 7th and 10th items were combined according to the modification indices. However, the error rates of items 18 and 19 were combined. When the fit values of the confirmatory factor analysis were examined, the goodness of fit index values of the scale were calculated as CMIN / DF (X2 / sd) = 4.99; RMSEA $=.08 ; \mathrm{SRMR}=0.439 ; \mathrm{GFI}=.94 ; \mathrm{AGFI}=.90 ; \mathrm{NFI}=.92 ; \mathrm{CFI}=, 93$. It can be said that the model obtained as a result of this confirmatory factor analysis remained within acceptable goodness of fit index values.

\section{Collecting Qualitative Data}

The interview technique was used while collecting qualitative data. The interview technique is very powerful in revealing the participants' feelings, experiences, and opinions. A semistructured interview form, consisting of three questions and developed by the researcher, was used in the interviews according to the quantitative research findings. Some features of semi-structured interviews are as follows: Semi-structured interview forms do not have predetermined question details and statements. The interview usually consists of questions to be revealed. Different and specific information is collected from each of the participants. Questions are often flexible (Merriam, 2013).

\section{Data Analysis}

SPSS and AMOS programs were used to analyze the data. AMOS program was used to test the model for the confirmatory factor analysis of the scales and literature review. The fit indices taken into account in the evaluation of model fit in the examination of fit are the level of significance (p), chi-square/degrees of freedom (X2 / sd = CMIN / DF) and normed fit index (NFI), root mean square error of approximation ( RMSEA), standardized root mean square residual (SRMR), comparative fi $t$ index (CFI), the goodness of fi $t$ index (GFI), adjusted goodness of fit index (AGFI).

The qualitative data collected with the semi-structured interview form was recorded using the Microsoft Word program. When this data was saved in the Word document, it was written in the same way without any changes, and the accuracy of the data was constantly checked. After this stage, the data obtained were transferred to the NVivo program. In the next step, content analysis was used to analyze these data. The thickness of each of these arrows is determined by dividing the number of citations made to the relevant sub-theme by five. In other words, the maximum number of citations to a theme and sub-theme can be $5 \mathrm{k}$, while the least citation can be $1 \mathrm{k}$. 


\section{Results}

\section{Findings Regarding the Quantitative Part of the Study}

In this part of the research, findings related to the quantitative part will be included.

\section{Findings regarding the first question of the study}

Regarding the first question of the study, correlation analysis was conducted to determine the relationship between authentic leadership, motivation, and job satisfaction. When it is examined, there is a moderately positive and significant relationship between motivation and job satisfaction $(\mathrm{r}=.493)$; relationship between authentic leadership and job satisfaction $(\mathrm{r}=$ .539); between authentic leadership and motivation $(\mathrm{r}=.355)$.

Table 1: Correlation Table for the Relationship between Authentic Leadership, Motivation and Job Satisfaction

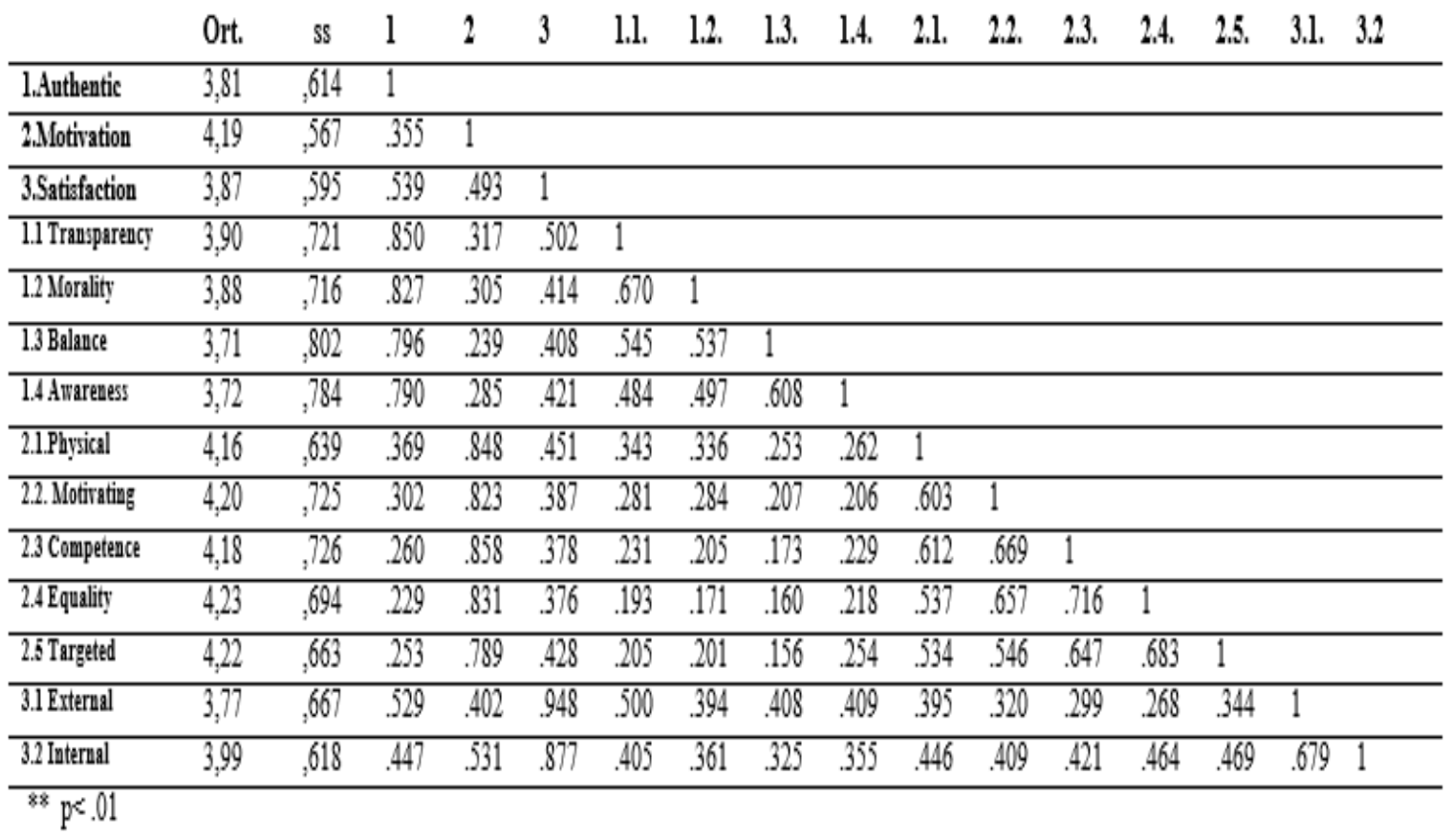

\section{Research findings regarding the second, third, fourth, and fifth questions}

The theoretical model, which emerged based on the literature review and aims to reveal the effect of authentic leadership on teachers' motivation and job satisfaction, was examined with a structural equation model using the AMOS program. The predictions to explain the relationship between authentic leadership, teacher motivation, and job satisfaction are shown in the figure below. 


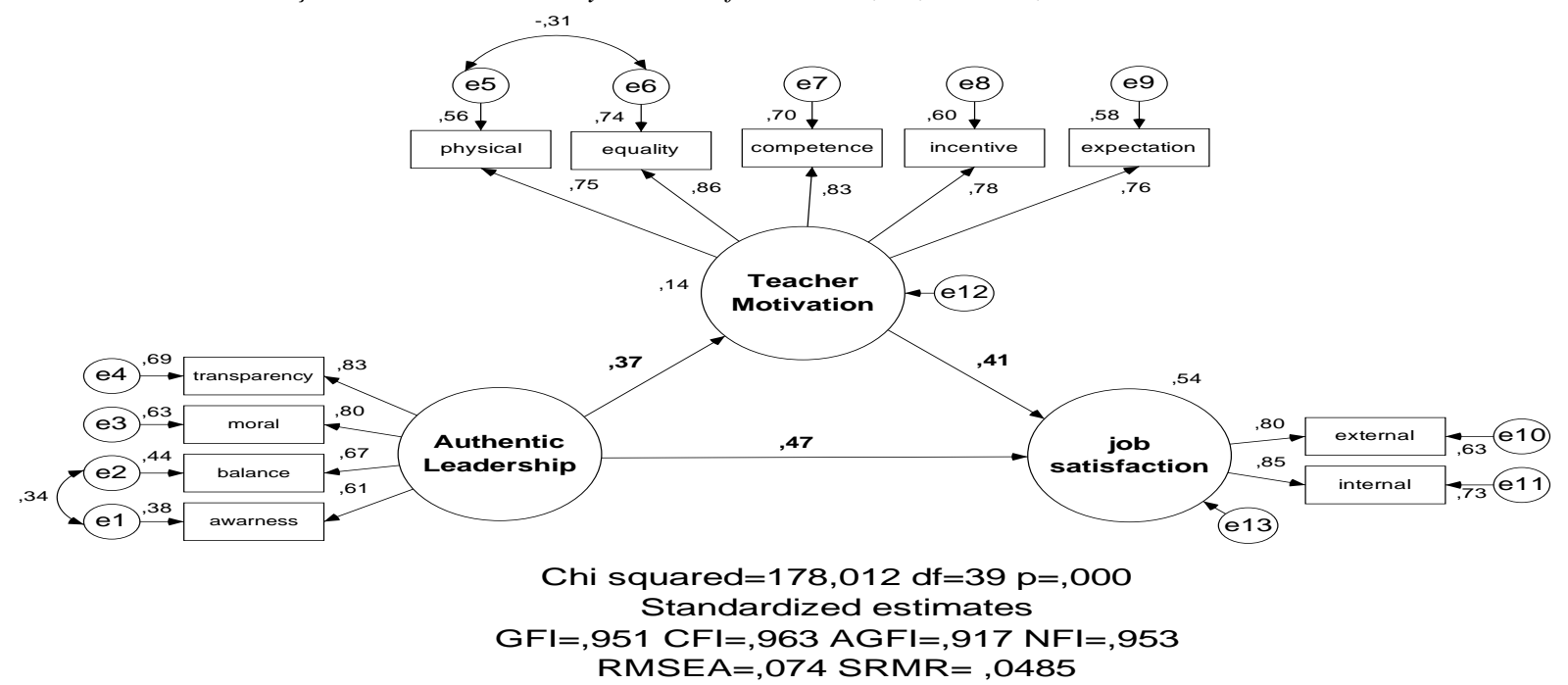

Figure 1. Results regarding the structural equation model

When the fit values of the the target model analysis were examined, the goodness of fit index values of the scale were calculated as CMIN / DF $(\mathrm{X} 2 / \mathrm{sd})=4.56$; $\mathrm{RMSEA}=.074$; $\mathrm{SRMR}=0.485 ; \mathrm{GFI}=.951 ; \mathrm{AGFI}=.917 ; \mathrm{NFI}=.953 ; \mathrm{CFI}=, 963$. When the statistical values regarding the fit of the structural equation model are examined, it can be said that the model fit values are within acceptable values, and the model is accepted in the context of the fit indices.

The Chi-Square fit test (X2) is the first value to be looked at in the goodness of fit index and is evaluated in terms of its ratio with degrees of freedom (SD). Therefore, it can be said that a good fit value X2 / SD ratio of less than five is an acceptable fit. For this study, the X2 / SD value was found to be $178.01 / 39=4.56$. When considered in the context of these results, it is observed that the X2 / SD value meets the acceptable fit (Meydan \& Şeşen, 2001).

Second, fit indices based on residues such as AGFI, GFI, and SRMR were examined. If the value of the SRMR, which is the square root of the standardized residual means, is less than 05 , it can be said that it is within the good fit value limit. In this study, it was observed that SRMR = 0485 fit well. GFI, which is a value showing variance and covariance, is between 0.95 and 1.00 with the sample size increase. In this study, GFI $=951$ millet has revealed that it has a good fit. It was observed that AGFI $=917$, which reveals the large sample size, shows a good fit (Bayram, 2010).

Third, the NFI value, which is unstable in small sample volumes, was examined first. It can be said that it complies well with the NFI =, 953 value. On the other hand, CFI =, known for its sensitivity to the number of samples, remained within the limit of acceptable 
values with a value of 963 . Finally, RMSEA =, 074, remained within the limit of acceptable values (Bayram, 2010; Meydan \& Şeşen, 2001).

Regarding the second question of the study, when the standardized regression coefficients are examined, it can be said that authentic leadership has a positive and significant effect on teacher motivation $(\beta=, 37 ; \mathrm{P}<, 01)$. The critical rate for this value is 7.53, and its standard error is 05 . In other words, when the authentic behaviors of principals increase in schools, the motivation of teachers increases.

When examining the standardized regression coefficients in the context of the third question of the study, it can be said that teachers' motivation has a positive and significant effect on job satisfaction $(\beta=, 41 ; \mathrm{P}<, 01)$. The critical rate for this value is 9.60 , and its standard error is 05 . In this context, it can be said that when teachers' motivation increases, their job satisfaction also increases.

The regression coefficients standardized within the scope of the fourth question of the study show that authentic leadership has a positive and significant effect on teacher job satisfaction $(\beta=, 47 ; \mathrm{P}<, 01)$. The critical rate for this value is 8.39 , and its standard error is 06. In light of this finding, it can be said that as the authentic behaviors of administrators increase, their job satisfaction increases.

When the findings were examined in the context of the fifth research question of the study, it was found that authentic leadership and motivation explained job satisfaction significantly by $54 \%$. In other words, it can be said that the reason for the change in job satisfaction is $54 \%$ due to authentic leadership and motivation.

\section{Findings Regarding Qualitative Research}

In this section, findings related to qualitative research are given.

\section{Research findings concerning the sixth question of the study.}

For the qualitative part, the diagram obtained from the participants' views on authentic behaviors that motivate teachers is shown in the figure below. In addition, the themes formed from the views about authentic behaviors that motivate teachers and the reference views that led to the emergence of these themes are given below. 


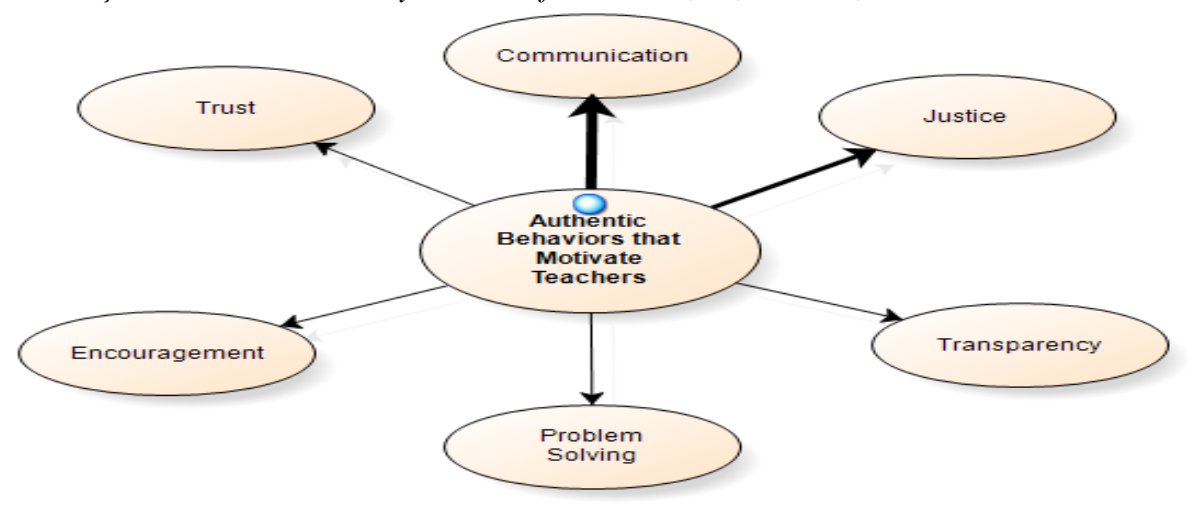

Figure 2. Authentic behaviors that motivate teachers

Communication: As a result of the qualitative analysis, "communication" was the most cited theme. Accordingly, it can be said that teachers believe that authentic behavior affects their communication. Sample expressions regarding the views on the communication sub-theme are given below.

"... talk to the administrator and the teachers without separating anyone... (s, 1)"

"... such behaviors are very important in establishing an effective communication in the school environment, setting a goal and achieving this goal ... (s, 2)"

"... For example, I am a physical education teacher; I have a manager I can communicate with. Therefore, I employ three teams, not one... (T, 4)"

Justice: One of the authentic behaviors that motivate teachers due to the qualitative analysis is the theme of "justice". Examples of the sub-theme of justice are given below.

"... treating everyone equally and not discriminating increases motivation.

Because as long as they are treated fairly, they do not show any privileges to anyone... $(\mathrm{s}, 6) "$

"... she was very kind. Her position and status do not affect her communication with people. She treated every teacher fairly $(s, 7)$ "

Transparency: As a result of qualitative analysis, it can be said that one of the authentic behaviors that motivate teachers is "transparency". Regarding the sub-theme of transparency, "... manager to speak anything for or against my staff about someone who speaks against you, I do not want to hear this... (s, 11) "opinion can be given as an example.

Problem Solving: As a result of qualitative analysis, it can be said that one of the authentic behaviors that provide teachers' motivation is "problem-solving." Regarding the problem- 
solving sub-theme, "...of urgently solving problems and finding new alternatives in relations with parents... (s, 3)" may be an example.

Encouragement: It can be said that another authentic behavior that motivates teachers is "encouragement". Regarding the sub-theme of encouragement, "... besides, our manager makes us happy. We want this school to be successful $(\mathrm{s}, 8)$ " can be an example.

Trust: Another authentic behavior that motivates teachers can be said to be "trust". Regarding the trust sub-theme, "... the administrator's trust in the teacher is very important, for example, it is very important to contribute to the projects we do... (s, 8)".

\section{Research findings regarding the seventh question of the study}

For the qualitative part, the data obtained from the participants' opinions about the motivation that provides job satisfaction from the teachers are shown in the figure below.

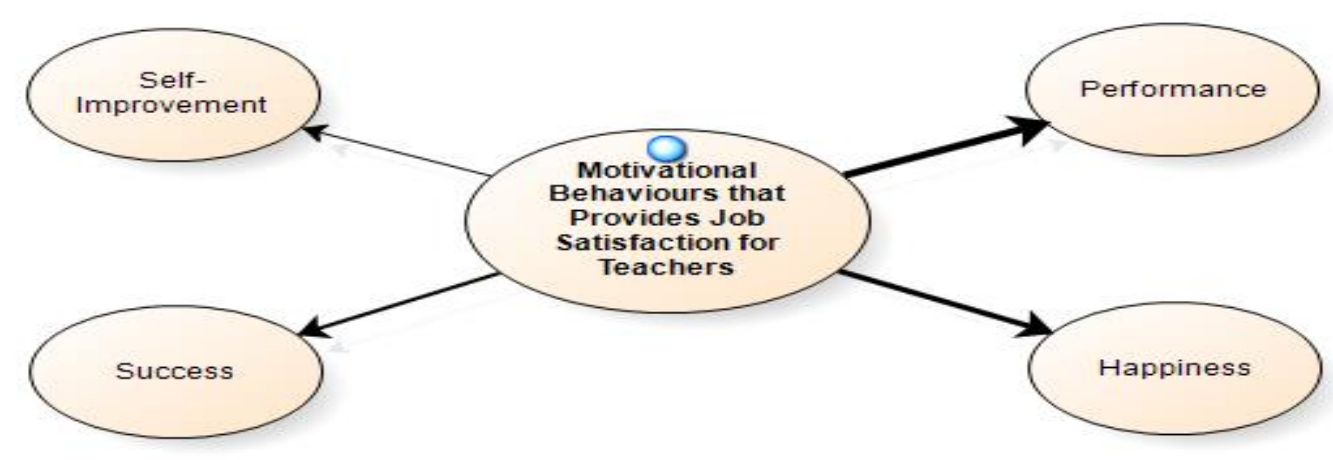

Figure 3. Motivational behaviors contribute to teachers' job satisfaction.

Performance: As a result of the qualitative analysis, the highest load on motivating behaviors that provide teachers' job satisfaction was made to the "performance" theme. Accordingly, it can be said that teachers believe that the motivational behavior that affects their job satisfaction is performance. Examples of the views on the performance sub-theme are given below. 
"... sometimes, you do five activities for one class. If your motivation is low, you can do an activity for one hour... (s, 4)"

"... when my motivation is high, I feel like there is nothing I cannot accomplish, and when my life energy is high, this reflects on my students, they are more efficient and positive. (s, 7) "

"... if I think that I have a fair work environment, that is, if I think that I will evaluate it only because of my job performance, my motivation and work success will be high first ... (T, 11)"

Happiness: Another theme that provides teachers' job satisfaction due to the qualitative analysis is "happiness". Accordingly, it can be said that teachers believe that happiness is one of the motivational behaviors that most affect their job satisfaction. Examples of the views on the happiness sub-theme are given below.

"... If you are not motivated by your job, you cannot experience job satisfaction. Without motivation, it will not bring results and success... (s, 5)"

"... I think there is a domino effect between these two. As a result, it makes you happy ..... (s, 8)"

Success: As a result of the qualitative analysis, another loading for motivating behaviors that provide teachers' job satisfaction was made to the theme of "success". Accordingly, it can be said that teachers believe that one of the motivational behaviors that most affect their job satisfaction is a success. Examples of views on the sub-theme of success are given below.

"... If a teacher is motivated by his job, no one can stop him. He can open new horizons to his students and leave a mark in their lives. He gets his share from this in the classroom environment. The positive change in the students is also reflected in the parents. Reaching our goals will be inevitable... (s, 3)"

Self-Improvement: It can be said that "self-development" is another motivating behavior that provides teachers' job satisfaction. Regarding the sub-theme of self-development, "... when we attribute this negative situation to ourselves, not to the student, our motivation is damaged. teacher models that cannot improve themselves and are not open to innovations.... $(\mathrm{s}, 5)$ "may be an example.

The diagram obtained from the participants 'opinions of the teachers' interest in authentic behaviors that provide job satisfaction is shown in the figure. In addition, the themes arising 
from the teachers' views on authentic behaviors that provide job satisfaction and the reference views that led to these themes are given below.

\section{Research findings regarding the eighth question of the study}

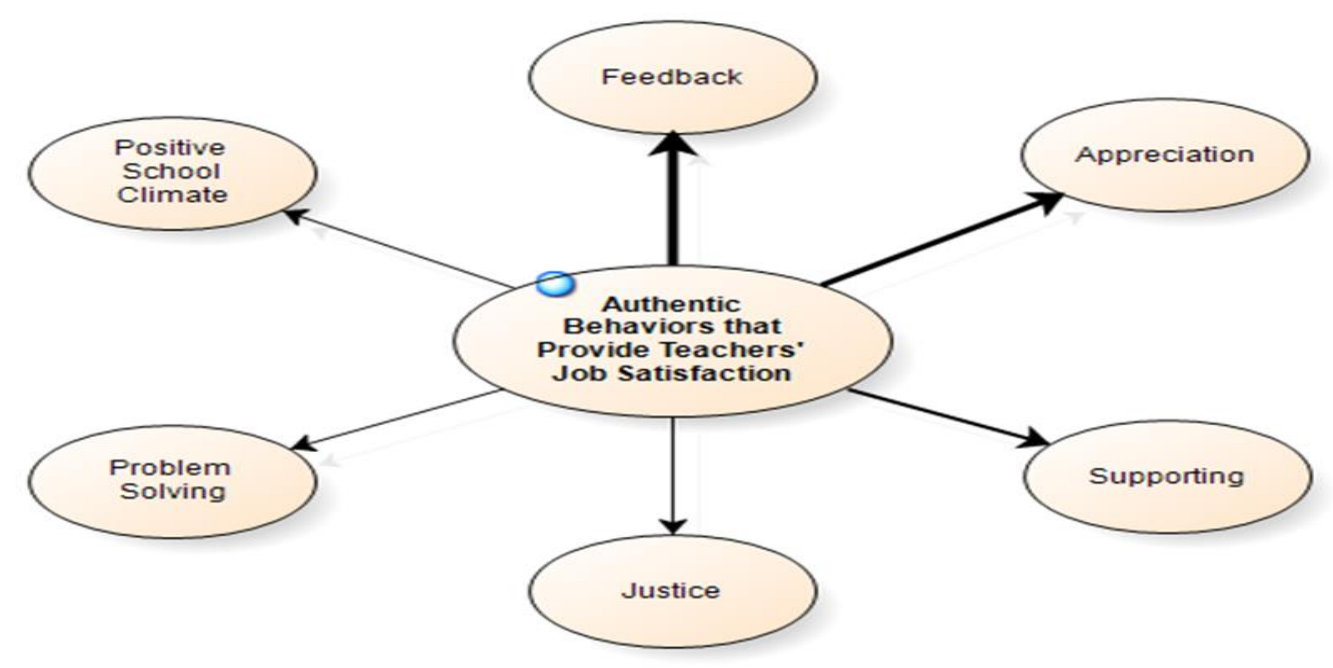

Figure 4. Authentic behaviors that provide job satisfaction

Feedback: As a result of the qualitative analysis, it was observed that the first of the most loadings on authentic behaviors that provide teachers' job satisfaction was made to the "feedback" theme. Accordingly, it can be said that one of the authentic behaviors that most affect teachers' job satisfaction is feedback. Examples of the views on the feedback subtheme are given below.

"... also, the school administrator's expectation from his teacher to do only his job and giving positive feedback, as a result, ensures that the teacher gains job satisfaction in his job ... (s, 2)"

"... It is always what I want to evaluate by looking at the work I give. This causes an increase in job satisfaction. But looking directly from the negative perspective and criticizing my negative side affects my job satisfaction negatively... (T, 6)"

"... if there is no feedback, this will not work. It is a fact that our job satisfaction will increase in particularly when we receive constructive criticism from the management, students, and teachers ... (s, 10)"

Appreciation: As a result of the qualitative analysis, it was observed that the second of the most loadings on authentic behaviors that provide job satisfaction of teachers was made on the theme of "appreciation". Accordingly, it is observed that one of the authentic behaviors 
that most affect teachers' job satisfaction is appreciation. Examples of the views on the subtheme of appreciation are given below.

"... for example, it is very important to be verbally appreciated or to get a certificate of achievement. When you are appreciated, the pleasure you get from work increases.... (s, 4)"

"... I think that the administrator will increase job satisfaction by using the reward mechanism... (s, 11)"

Supporting: As a result of the qualitative analysis, it can be said that the third of the most loadings on authentic behaviors that provide teachers' job satisfaction is "supported". An Example of the views on the sub-theme of support is given below.

"... knowing that he is supported in all kinds of activities in the business environment opens new horizons for the teacher and begins to ask what else he can produce? This is the most important question to prevent stagnation in the education community ... $(\mathrm{s}, 3)^{\prime \prime}$

Justice: As a result of the qualitative analysis, one of the authentic behaviors that provide teachers' job satisfaction is "justice." Regarding the sub-theme of justice, the view can be an example "... I think that it should not only act according to the principle of equality but also should be fair. I think that it should not put the employee and the one who does not work with the bearer should make positive discrimination on the employee. ... $(\mathrm{s}, 7)$ "

Problem Solving: It can be said that "problem-solving" is another authentic behavior that provides teachers' job satisfaction. Regarding the problem-solving sub-theme, opinion can be given as an example "... even if we are in a higher office outside the school, we can get help to solve our problems. For example, when there are projects, our managers solve the problem themselves. If they cannot solve it, they go to a higher authority for us and try to help us. When you see this effort, you become happy... (s, 7)"

Positive School Climate: It can be said that another authentic behavior that provides teachers' job satisfaction is "positive school climate". Regarding the sub-theme of the positive school climate opinion can be an example "... it is important to hear the good morning because it makes you unhappy to be asked to account when you are 2-3 minutes late, you reflect this while doing your job. ... $(\mathrm{s}, 5)$ " 


\section{Discussion and Conclusion}

When the research results are considered in a quantitative context, it has been determined that there is a positive relationship between the authentic leadership behaviors of school administrators and teachers' motivations. However, it has been revealed that authentic behaviors of school administrators have a positive effect on teachers' motivation. The qualitative research results also support these results. As a result of the qualitative research conducted, it was revealed that positive communication, appropriate behavior, transparency, problem-solving, encouragement of teachers, and trust-oriented behaviors put forward by school administrators in the context of authentic leadership positively affect teachers' motivation. In summary, it is thought that school administrators 'self-awareness in the context of authentic leadership, a balanced assessment of the knowledge, and internalized understanding of morality, and being transparent in their relationships positively affect teachers' motivation. Özerten (2018) revealed that the authentic leadership behaviors of school administrators have a positive relationship with teachers' motivations. He stated that $63 \%$ of the reason for the change in teachers' motivation was authentic leadership. Okcu and Anık (2017) revealed that authentic leadership and motivation have a moderate and positive relationship. It was revealed that $31 \%$ of the reason for the change in motivation originated from authentic leadership. Ahmad, Zafar, \& Shahzad (2015) found a moderate and significant relationship between authentic leadership and intrinsic motivation. The same study stated that authentic leadership positively affects motivation (Ahmad, Zafar, \& Shahzad, 2015). Apart from these, many studies in the literature reveal the relationship between authentic leadership and motivation (Akhlaq \& Ahmed, 2013; Rempel, Holmes, \& Zanna, 1985; Guerrero, Lapalme \& Seguin, 2015; Shu, 2015; Walumba et al., 2008; Walumbwa et al. ., 2010; Wong \& Laschinger, 2013). (Ahmad, Zafar, \& Shahzad, 2015; Akhlaq \& Ahmed, 2013; Rempel, Holmes, \& Zanna, 1985; Guerrero, Lapalme, \& Seguin, 2015; Shu, 2015; Walumba vd., 2008; Walumbwa vd., 2010; Wong \& Laschinger, 2013).

It has been determined that there is a positive relationship between the authentic leadership behaviors of school administrators and teachers' job satisfaction. According to another result, it was revealed that authentic behaviors of school administrators had a positive effect on teachers' job satisfaction. Qualitative research results also support these two results. As a result of the qualitative research conducted, it was revealed that the behaviors of school administrators in the context of authentic leadership to give feedback, appreciate teachers, support teachers, be fair, problem-solving, and create a positive school 
climate positively affect teachers' motivation. In summary, school administrators 'selfawareness in the context of their authentic leadership characteristics, a balanced assessment of the knowledge, and internalized understanding of morality and being transparent in their relationships positively affect teachers' job satisfaction. Kılıç (2020) revealed in his research that authentic leadership affects job satisfaction moderately and significantly. However, he stated that $78 \%$ of the change in job satisfaction originated from authentic leadership and organizational justice. According to the study of Aydınoğlu (2020), there is a moderate and positive relationship between school administrators 'authentic leadership behaviors and teachers' job satisfaction. This result can be similar to other research results (Anseel \& Lievens, 2007; Azanza, Moriano, \& Molero, 2013; Chen, 2008; Penger \& Cerne, 2014; Wong \& Laschinger, 2013).

According to the study results, it was revealed that there is a positive relationship between teachers' motivation and job satisfaction and that their motivation positively affects their job satisfaction. This result has supported the qualitative research result with performance, self-actualization, feeling successful and happy, affecting job satisfaction in motivation. Apart from these, another quantitative research result is that the authentic leadership behaviors of school administrators cause a change in job satisfaction and motivation. In summary, it can be said that motivation affects job satisfaction and the reason for the positive change in job satisfaction is due to the authentic leadership behavior of the manager and the teachers' motivations. These results are similar to the results of other studies (Brown \& Peterson, 1994; Leroy et al., 2015; Kondalkar, 2007; Tella, Ayeni, \& Popoola, 2007; Wong \& Laschinger, 2013).

It was observed within the scope of this study that there is a positive relationship between authentic leadership, teacher motivation, and job satisfaction. All of these findings are supported by qualitative results. In this context, it is thought that raising the awareness of school administrators and teachers that these behaviors are interrelated in their in-service training will be beneficial in terms of the effectiveness of general education policies. In addition, it was observed that the authentic behaviors of school administrators made a positive change in job satisfaction and teachers' motivation. In this context, in pre-service and in-service training, it is recommended to raise the awareness of school administrators that they affect very important behaviors such as motivation and job satisfaction of teachers by creating a domino effect if they have self-awareness, correctly evaluate their knowledge, and reveal moral and transparent behaviors as a principle. 
Ethical Approval: This research was carried out with the permission of the Provincial Directorate of National Education dated 07/09/2018 and numbered 36648235-605.01E.15801683.

Conflict Interest: There is no conflict of interest to be declared by the authors.

Authors' Contributions: The first author contributed to the formation of the idea of the study, determination of the research method, and evaluation of the article. The second author contributed to the literature review, data collection, data analysis, and article writing 


\section{References}

Ahmad, I., Zafar, M. A., \& Shahzad, K. (2015). Authentic leadership style and academia's creativity in higher education institutions: intrinsic motivation and mood as mediators. Transylvanian Review of Administrative Sciences, 11(46), 5-19.

Akhlaq, A., \& Ahmed, E. (2013). The effect of motivation on trust in the acceptance of internet banking in a low-income country. International Journal of Bank Marketing, $31(2), 115-125$.

Alsat, O. Ç. (2016). Çalışan motivasyonunu etkileyen faktörlerin iş tatminine etkisini belirlenmesine yönelik bir uygulama [An application to determine the effects of factors affecting employee motivation on job satisfaction] (Doctoral Dissertation). Higher Education Council Thesis Center (No: 422500)

Anseel, F., \& Lievens, F. (2007). The long term impact of the feedback environment on job satisfaction: A field study in a Belgian context. Applied Psychology, 56(2), 254-266.

Arlı, M., \& Nazik, M. H. (2004). Bilimsel araştırmaya giriş (4. Baskı). Ankara: Gazi Kitabevi.

Avolio, B. J., \& Gardner, W. L. (2005). Authentic leadership development: Getting to the root of positive forms of leadership. The leadership Quarterly,16(3), 315-338.

Aydınoğlu, N. (2020). Yöneticilerin otantik ve paternalist liderlik davranışlarının ögretmenlerin motivasyon, iş tatmini ve örgüt bă̆lllı̆̆ına etkilerinin incelenmesi [Investigation Of The Effects Of Authentic And Paternalist Leadership Behavior Of Administrators On Teachers'motivation, Job Satisfaction And Organizational Commitment]. İstanbul Gelişim Üniversitesi.

Azanza, G., Moriano, J.A., \& Molero, F. (2013). Authentic leadership and organizational culture as drivers of employees' job satisfaction. Journal of Work and Organizational Psychology 29(2), 45-50.

Balc1, A. (2009). Sosyal bilimlerde araştırma (7. baskı). Ankara: Pegem A Yayıncılık.

Bartlett, J. E., Kotrlik, JW, \& Higgins, CC (2001). Organizational research: Determining appropriate sample size in survey research. Information Technology, Learning, and Performance Journal, 19(1), 43-50.

Barutçugil, İ. (2004). Organizasyonlarda duyguların yönetimi [Managing emotions in organizations]. İstanbul: Kariyer Yayınları.

Bayram, N. (2010). Yapısal eşitlik modellemesine giriş AMOS Uygulamaları/Introduction to structural equation modeling AMOS Applications]. Bursa: Ezgi Kitabevi. 
Begley, P. T. (2004). Understanding valuation processes: exploring the linkage between motivation and action. International Studies in Educational Administration, 32(2), 417.

Benson, J. D. (2008). Leadership and Motivation. Research Starters: Business

Bil, E. (2018). Ortaöğretim okullarının öğrenen örgüt, örgütsel güven ve iş doyumu düzeyleri arasındaki ilişki[The relationship between the learning organization, organizational trust and job satisfaction levels of secondary schools] (Doctoral Dissertation). Higher Education Council Thesis Center (No: 494132)

Black, A. E., \& Deci, E. L. (2000). The effects of instructors' autonomy support and students' autonomous motivation on learning organic chemistry: A self-determination theory perspective. Science Education, 84(6), 740-756.

Brown, S. P., \& Peterson, R. A. (1994). The effect of effort on sales performance and job satisfaction. Journal of Marketing, 58(2), 70-80.

Bursalığlu, Z. (2015). Okul yönetiminde yeni yapı ve davranış [The new structure and behavior in school management]. Ankara: Pegem.

Can, Y., \& Soyer, F. (2008). Beden eğitimi öğretmenlerinin sosyo-ekonomik beklentileri ile iş tatmini arasındaki ilişki [The relationship between the socio-economic expectations of physical education teachers and job satisfaction]. Gazi Ĕ̈itim Fakültesi Dergisi, 28(1), 61-74.

Chen, L. H. (2008). Job satisfaction among information system (IS) personnel. Computers in Human Behavior, 24(1), 105-118.

Clapp-Smith, R., Vogelgesang, G. R., \& Avey, J. B. (2009). Authentic leadership and positive psychological capital the mediating role of trust at the group level of analysis. Journal of Leadership \& Organizational Studies, 15(3), 227-240.

Colquitt, J. A., Conlon, D. E., Wesson, M. J., Porter, C. O., \& Ng, K. Y. (2001). Justice at the millennium: a meta-analytic review of 25 years of organizational justice research. Journal of Applied Psychology, 86(3), 425-445.

Conlow, R. (1999). Excellence in supervision. Crisp Learning.

Creswell, J. W. (2013). Qualitative, quantitative, and mixed methods approaches. Thousand Oaks, CA: Sage

Creswell, J. W., \& Clark, V. L. P. (2014). Designing and conducting mixed methods research. Sage Publication.

Creswell, W.J. (2017). A concise introduction to mixed methods research. Sage Publication. 
Darvish, H. ve Rezaei, F. (2011) The impact of authentic leadership on job satisfaction and team commitment. Management and Marketing, 6(3):421-436.

Datta, B. (2015). Assessing the effectiveness of authentic leadership. International Journal of Leadership Studies, 9(1), 19-32.

Dinh, J. E., Lord, R. G., Gardner, W. L., Meuser, J. D., Liden, R. C., \& Hu, J. (2014). Leadership theory and research in the new millennium: Current theoretical trends and changing perspectives. The Leadership Quarterly, 25(1), 36-62.

Durdağı, A., \& KILIÇ, M. E. Öğretmen motivasyonu ölçeğinin geliştirilmesi [Development of Teacher Motivation Scale]. Turkish Journal of Educational Studies, 7(2), 16-41.

Dweck, C. S., \& Leggett, E. L. (1988). A social-cognitive approach to motivation and personality. Psychological Review, 95(2), 256-273.

Elliot, A. J., \& Covington, M. V. (2001). Approach and avoidance motivation. Educational Psychology Review, 13(2), 73-92.

Ersözlü, A. (2012). Okul yöneticilerinin yönetsel güçlülük düzeylerinin ögrretmenlerin örgütsel bağlllık, örgütsel vatandaşlık davranışları ve iş doyumuna etkisi[The effect of school administrators 'managerial strengths on teachers' organizational commitment, organizational citizenship behaviors and job satisfaction] (Doctoral Dissertation). Higher Education Council Thesis Center (No: 422500)

Gardner, W. L., Avolio, B. J., Luthans, F., May, D. R., \& Walumbwa, F. (2005). “Can you see the real me?" A self-based model of authentic leader and follower development. The Leadership Quarterly, 16(3), 343-372.

George, B. \& Sims, P. (2010). True north: Discover your authentic leadership. San Francisco: John Wiley \& Sons.

George, J. M., Jones, G. R., \& Sharbrough, W. C. (1996). Understanding and managing organizational behavior. (3. Edition). Reading, MA: Addison-Wesley.

Giallonardo, L. M., Wong, C. A., \& Iwasiw, C. L. (2010). Authentic leadership of preceptors: predictor of new graduate nurses' work engagement and job satisfaction. Journal of Nursing Management, 18(8), 993-1003

Glynn, M. \& Dejordy, R. (2010). Handbook of leadership theory and practice. N. Nohria\& R. Khurana (Ed.), Leadership trough an organization behavior. Boston: Harvard Business Press.

Guerrero, S., Lapalme, M. È., \& Séguin, M. (2015). Board chair authentic leadership and nonexecutives' motivation and commitment. Journal of Leadership \& Organizational Studies, 22(1), 88-101. 
Hellriegel , D., Slocum, J. W., \& Woodman, R. W. (2001). Organization behavior. St. Paul, Minn., West publishing comp. Les Cahiers de la Solidarité.

Henderson, J. E., \& Hoy, W. K. (1982). Leader authenticity: The development and test of an operational measure. Educational and Psychological Research, 3(2), 63 - 75.

Hoy, W. K., \& Miskel, C. G. (1987). Educational administration: Theory, research, and practice. Random House Trade.

Ilies, R., Morgeson, F. P., \& Nahrgang, J. D. (2005). Authentic leadership and eudaemonic well-being: Understanding leader-follower outcomes. The Leadership Quarterly, 16(3), 373-394.

Ilies, R., Morgeson, F. P., \& Nahrgang, J. D. (2005). Authentic leadership and eudaemonic well-being: Understanding leader-follower outcomes. The Leadership Quarterly, 16(3), 373-394.

Isaac, R. Z., Wilfred, J. P., \& Douglas, C. (2001). Leadership and motivation: The effective application of expectancy theory. Journal of Managerial Issues, 13(2), 1045-3695

Karaköse, T., \& Kocabaş, İ. (2006). Özel ve devlet okullarinda öğretmenlerin beklentilerinin 1Ş doyumu ve motivasyon üzerine etkileri. [The effects of teachers' expectations on job satisfaction and motivation in private and public schools ]. Eğitimde Kuram ve Uygulama, 2(1), 3-14.

Karasar, N. (1998). (8. Baskı Bilimsel araştırma yöntemi.). Ankara: Nobel Yayıncılık.

Karataş, S., \& Güleş, H. (2010). İlköğretim okulu öğretmenlerinin iş tatmini ile örgütsel bağlılığı arasındaki ilişki. [The relationship between primary school teachers' job satisfaction and organizational commitment ]. Uşak Üniversitesi Sosyal Bilimler Dergisi, 3(2), 74-89.

Kernis, M. H. (2003). Toward a conceptualization of optimal self-esteem. Psychological Inquiry, 14(1), 1-26.

Kılıç, M. Y. (2020). Otantik Liderlik Davranışlarının, Örgütsel Adalet ve Öğretmenlerin İş Tatmini Üzerine Etkisinin İncelenmesi. [Examining the Effect of Authentic Leadership Behaviors on Organizational Justice and Teachers' Job Satisfaction]. Kastamonu Eğitim Dergisi, 28(6), 2271-2283.

Kundak, Z., Hanife, Üzel., Keleş, A., \& Eğicioğlu, H. (2015). Bir üniversite hastanesinde hemşirelik mesleğinde iş tatmini ve motivasyon[Job satisfaction and motivation in the nursing profession in a university hospital]. Kocatepe T1p Dergisi, 16(1), 1-10.

Lawler, E. E. (1973). Motivation in work organizations. Monterey, CA: Brooks. 
Leroy, H., Anseel, F., Gardner, W. L., \& Sels, L. (2015). Authentic leadership, authentic followership, basic need satisfaction, and work role performance: A cross-level study. Journal of Management, 41(6), 1677-1697.

Locke, E.A. (1976), “The nature and causes of job satisfaction”, in Dunnette, M.D. (Ed.), Handbook of Industrial and Organizational Psychology, Rand McNally, Chicago, IL, pp. 1297-349

Luthans, F., Norman, S., \& Hughes, L. (2006). Authentic leadership: A new approach for a new time. In Inspiring leaders. London: Routledge, Taylor \& Francis.

Madenoğlu, C., Uysal, Ş., Sarıer, Y., \& Banoğlu, K. (2014). Okul müdürlerinin etik liderlik davranışları ile öğretmenlerin iş doyumlarının örgütsel bağlılıkla ilişkisi. [The relationship between school principals 'ethical leadership behaviors and teachers' job satisfaction with organizational commitment. ]. Kuram ve Uygulamada Egitim Yönetimi Dergisi, 20(1), 47-69.

Maslow, A. H., Frager, R., \& Fadiman, J. (1970). Motivation and personality (Vol. 2, pp. 1887-1904). New York: Harper Bothers.

McNeese-Smith, D. K. (1997). The influence of manager behavior on nurses' job satisfaction, productivity, and commitment. Journal of Nursing Administration, 27(9), 47-55.

Merriam, S. B. (2013). Introduction to qualitative research. Qualitative research in practice: Examples for discussion and analysis, 1(1), 1-17.

Meydan, H. C. \& Şeşen, H. (2011). Yapısal eşitlik modellemesi Amos Uygulaması [Structural equation modeling Amos Application]. Ankara: Detay Yayınc1lık.

Okcu, V. \& Anık, S.( 2017). Okul Yöneticilerinin Otantik Liderlik Davranışları İle Öğretmenlerin Motivasyon ve Mobbing (Yıldırma) Yaşama Düzeyleri Arasındaki İlişkilerin İncelenmesi [Examination of the Relationships Between School Administrators 'Authentic Leadership Behaviors and Teachers' Levels of Motivation and Mobbing]. Anadolu Ĕ̌gitim Liderliği ve Ö̆̆retim Dergisi, 5(2), 63-85.

Özerten, K. N. (2018). Okul yöneticilerinin algllanan otantik liderlik özelliklerinin ögretmenlerin mesleki motivasyonuna etkisi [The effect of perceived authentic leadership characteristics of school administrators on the professional motivation of teachers].İstanbul Sabahattin Zaim Üniversitesi, Sosyal Bilimler Enstitüsü, Eğitim Bilimleri Anabilim Dal. 
Penger, S., \& Černe, M. (2014). Authentic leadership, employees' job satisfaction, and work engagement: A hierarchical linear modelling approach. Economic researchEkonomska istraživanja, 27(1), 508-526.

Rempel, J. K., Holmes, J. G., \& Zanna, M. P. (1985). Trust in close relationships. Journal of Personality and Social Psychology, 49(1), 95.-112.

Robbins, S. P., \& Judge, T. A. (2015). Organizational behaviour. New Jersey: Pearson Prentice Hall

Robbins, S. P., DeCenzo, D. A., \& Coulter, M. K. (2008). Fundamentals of management: essential concepts and applications. Upper Saddle River, NJ: Pearson Prentice Hall.

Savaş, A. C. (2012). Okul müdürlerinin duygusal zekâ ve vduygusal emek yeterliklerinin, öğretmenlerin iş doyumu düzeylerine etkisi [The effect of school principals 'emotional intelligence and $\mathrm{v}$ emotional labor competencies on teachers' job satisfaction levels ] (Doctoral Dissertation). Higher Education Council Thesis Center. ( No: 320035)

Serinkan, C. (2008). Liderlik ve motivasyon geleneksel ve güncel yaklaşımlar [Leadership and motivation traditional and current approaches]. Ankara: Nobel Yayınc1lik.

Shamir, B., \& Eilam, G. (2005). "What's your story?” A life-stories approach to authentic leadership development. The Leadership Quarterly, 16(3), 395-417.

Shu, C. Y. (2015). The impact of intrinsic motivation on the effectiveness of leadership style towards on work engagement. Contemporary Management Research, 11(4).

Şimşek, M. Ş., Çelik, A., \& Akgemci, T. (2014). Davranış bilimlerine giriş ve örgütlerde davranış [Introduction to behavioral science and behavior in organizations]. Konya: Eğitim Kitabevi.

Tan, Ç. (2012). İlköğretim okul yöneticilerinin takım liderlik davranışlarının öğretmenlerin iş doyumu, örgütsel adanmışlık ve örgütsel vatandaşlık düzeylerine etkisi [The effect of primary school administrators 'team leadership behaviors on teachers' job satisfaction, organizational commitment and organizational citizenship levels](Doctoral Dissertation). Higher Education Council Thesis Center. (No: 4300428)

Teddlie, C., \& Tashakkori, A. (2015). Karma yöntem araştırmalarının temelleri (T. Dede, \& S. B. Demir, Çev. Ed.) Ankara: Anı Publishing.

Tella, A., Ayeni, C. O., \& Popoola, S. O. (2007). Work motivation, job satisfaction, and organisational commitment of library personnel in academic and research libraries in Oyo State, Nigeria. Library Philosophy and Practice, 9(2), 3-13. 
Toker, B. (2007). Konaklama İşletmelerinde İş Doyumu: Demografik Değişkenlerin İş̧ Doyumu Faktörlerine Etkisi Üzerine Bir Çalışma [Personality and leadership: managerial research, theories and interpretations with universal dimensions]. Journal of Yasar University, 2(6), 591-615.

Walumbwa, F. O., Avolio, B. J., Gardner, W. L., Wernsing, T. S., \& Peterson, S. J. (2008). Authentic leadership: Development and validation of a theory-based measure. Journal of Management, 34(1), 89-126.

Walumbwa, F. O., Christensen, A. L., \& Hailey, F. (2011). Authentic leadership and the knowledge economy: Sustaining motivation and trust among knowledge workers. Organizational Dynamics, 40(2), 110-118.

Walumbwa, F. O., Luthans, F., Avey, J. B., \& Oke, A. (2011). Retracted: Authentically leading groups: The mediating role of collective psychological capital and trust. Journal of Organizational Behavior, 32(1), 4-24.

Walumbwa, F. O., Wang, P., Wang, H., Schaubroeck, J., \& Avolio, B. J. (2010). Psychological processes linking authentic leadership to follower behaviors. The Leadership Quarterly, 21(5), 901-914.

Weiss, D. J., Dawis, R. V., England, G. W., \& Lofquist, L. H. (1967). Manual for the Minnesota Satisfaction Questionnaire: Minnesota studies in vocational rehabilitation. Minneapolis: Industrial Relations Center, University of Minnesota.

Wernsing, T. (2018). Leader Self-Awareness and Follower Psychological Empowerment Across Cultures. In Authentic Leadership and Followership. London: Palgrave Macmillan.

Wong, C. A., \& Cummings, G. G. (2009). The influence of authentic leadership behaviors on trust and work outcomes of health care staff. Journal of Leadership Studies, 3(2), 6-23.

Wong, C. A., \& Cummings, G. G. (2009). The influence of authentic leadership behaviors on trust and work outcomes of health care staff. Journal of Leadership Studies, 3(2), 6-23.

Wong, C. A., \& Laschinger, H. K. (2013). Authentic leadership, performance, and job satisfaction: the mediating role of empowerment. Journal of Advanced Nursing, 69(4), 947-959.

Wong, C. A., \& Laschinger, H. K. (2013). Authentic leadership, performance, and job satisfaction: the mediating role of empowerment. Journal of Advanced Nursing, 69(4), 947-959. 
Wong, C. A., Laschinger, H. K., \& Cummings, G. G. (2010). Authentic leadership and nurses' voice behaviour and perceptions of care quality. Journal of Nursing Management, 18(8), 889-900.

Yıldırım, İ., Akan, D., \& Yalçın, S. (2017). Sınıf öğretmenlerinin iş doyumu ve okul etkililiği algıları arasındaki ilişki. [ The relationship between classroom teachers' job satisfaction and school effectiveness perceptions.]. Erzincan Üniversitesi Ĕ̈itim Fakültesi Dergisi, 19(1), 69-81.

Yılmaz, A., \& Ceylan, Ç. B. (2011). İlköğretim okul yöneticilerinin liderlik davranış düzeyleri ile öğretmenlerin iş doyumu ilişkisi. [Relationship between primary school administrators 'leadership behavior levels and teachers' job satisfaction. ]. Kuram ve Uygulamada Egitim Yönetimi Dergisi, 17(2), 277-394.

Yılmaz, E., \& Aslan, H. (2013). Öğretmenlerin iş yerinde yalnızlıkları ve yaşam doyumları arasındaki ilişkinin incelenmesi. [Examining the relationship between teachers' workplace loneliness and life satisfaction ] Pegem Ĕ̆itim ve Öğretim Dergisi, 3(3), 59-69.

Zamahani, M., Ghorbani, V., \& Rezaei, F. (2011). Impact of authentic leadership and psychological capital on followers' trust and performance. Australian Journal of Basic and Applied Sciences, 5(12), 658-667.

Zel, U. (2011). Kişilik ve liderlik: evrensel boyutlarıyla yönetsel açıdan araştırmalar, teoriler ve yorumlar[Personality and leadership: managerial research, theories and interpretations with universal dimensions]. Ankara: Nobel Yayın Dağıtı 